\title{
GM1 mediates the formation and maintenance of cytotoxic $A \beta$ oligomers
}

\author{
Dong Yan Zhang ${ }^{1}$, Jian Wang ${ }^{1}$, Rebecca M. Fleeman ${ }^{1,2,3}$, Madison K. Kuhn ${ }^{1,2,3,4}$, Matthew T. Swulius ${ }^{6}$, \\ Elizabeth A. Proctor ${ }^{1,2,3,4,5}$, and Nikolay V. Dokholyan ${ }^{1,4,6,7 *}$ \\ ${ }^{1}$ Department of Pharmacology, Penn State College of Medicine, Hershey, PA, 17033-0850, USA. \\ ${ }^{2}$ Department of Neurosurgery, Penn State College of Medicine, Hershey, PA, 17033-0850, USA \\ ${ }^{3}$ Center for Neural Engineering, Pennsylvania State University, University Park, PA \\ ${ }^{4}$ Department of Biomedical Engineering, Pennsylvania State University, University Park, PA \\ ${ }^{5}$ Department of Engineering Science \& Mechanics, Pennsylvania State University, University Park, PA \\ ${ }^{6}$ Departments of Biochemistry \& Molecular Biology, Penn State College of Medicine, Hershey, PA, 17033- \\ 0850, USA. \\ ${ }^{7}$ Department of Chemistry, Pennsylvania State University, University Park, PA \\ *Corresponding author: Nikolay V. Dokholyan, E-mail: dokh@psu.edu.
}

\begin{abstract}
The aggregation of amyloid beta $(A \beta)$ peptide is associated with Alzheimer's disease (AD) pathogenesis. Cell membrane composition, especially monosialotetrahexosylganglioside (GM1), is known to promote the formation of $A \beta$ fibrils, yet little is known about the roles of GM1 in the early steps of $A \beta$ oligomer formation. Here, by using GM1-contained liposomes as a mimic of neuronal cell membrane, we demonstrate that $G M 1$ is a critical trigger of $A \beta$ oligomerization and aggregation. We find that GM1 not only promotes the formation of $A \beta$ fibrils, but also facilitates the maintenance of $A \beta$ oligomers on liposome membranes. We structurally characterize the $A \beta$ oligomers formed on the membrane and find that GM1 captures $A \beta$ by binding to its arginine- 5 residue. To interrogate the mechanism of $A \beta$ oligomer toxicity, we design a new liposome-based $\mathrm{Ca}^{2+}$-encapsulation assay and provide new evidence for the $A \beta$ ion channel hypothesis. Finally, we conduct cell viability assay to determine the toxicity of $A \beta$ oligomers formed on membranes. Overall, by uncovering the roles of $\mathrm{GM} 1$ in mediating early $A \beta$ oligomer formation and maintenance, our work provides a novel direction for pharmaceutical research for AD.
\end{abstract}




\section{INTRODUCTION}

Alzheimer's disease is the most common neurodegenerative disorder, responsible for $60-70 \%$ of dementia cases (Burns and lliffe, 2009). The economic burden associated with caring for nearly 50 million people worldwide with $A D$ is estimated in the hundreds of billions of dollars annually (Vos et al., 2016). The pathophysiology of $A D$ is characterized by the accumulation of extracellular plaques, predominantly composed of amyloid beta $(A \beta)$, and cytoplasmic neurofibrillary tangles, mostly composed of tau protein. Despite multiple proposed hypotheses (Alves et al., 2015; Bartzokis, 2011; Cataldo et al., 2010; Deane and Zlokovic, 2007; Francis et al., 1999; Hardy and Allsop, 1991; Kandimalla et al., 2016; Miklossy, 2011; Mudher and Lovestone, 2002; Pisa et al., 2015; Su et al., 2008), the molecular etiology of the disease remains a mystery. One of the oldest and most central hypotheses, the amyloid cascade hypothesis, posits that the accumulation of $A \beta$ proteins in the brain is the primary cause of $A D$ pathogenesis, leading to tau pathology, neuroinflammation, synapse loss, and ultimately neuron death (Hardy, 2006; Hardy and Higgins, 1992; Iversen et al., 1995; Jakob-Roetne et al., 2009; Tanzi and Bertram, 2005). The amyloid cascade hypothesis was subsequently revised to $A \beta$ oligomers cascade hypothesis (Bernstein et al., 2009; Butterfield and Lashuel, 2010; Glabe, 2008; Matsumura et al., 2011; Quist et al., 2005), stating that small $A \beta$ oligomers (DeToma et al., 2012; Haass and Selkoe, 2007) rather than fibrils (Klein et al., 2001; Lambert et al., 2001) are the main toxic species, is an alternative to the original amyloid cascade hypothesis. The oligomer hypothesis has been gaining significant momentum, since numerous studies have shown that $A \beta$ oligomers are toxic to primary neurons, inhibit hippocampal long-term potentiation, and cause memory impairment in rat or mouse models (Karran et al., 2011; Martinez Hernandez et al., 2018). Mounting evidence, stemming from other neurodegenerative diseases, also support the oligomer hypothesis. For example, in amyotrophic lateral sclerosis, soluble superoxide dismutase (SOD1) oligomers (Choi and Dokholyan, 2021; Proctor et al., 2015; Redler et al., 2014) of disease-associated proteins, rather than insoluble aggregates (Zhu et al., 2018), are shown to be responsible for cytotoxicity. Insoluble SOD1 aggregates have been found to be protective against neuronal toxicity, potentially due to competition with soluble oligomers (Bieschke et al., 2011; Zhu et al., 2018).

The mechanism of $A \beta$ oligomer toxicity is unknown, but several studies (Anekonda et al., 2011; Bhowmik et al., 2015; Jang et al., 2007, 2010; Quist et al., 2005) show that $A \beta$ oligomers may disrupt the plasma membrane to upset ionic (especially calcium) homeostasis. A number of mechanisms by which $A \beta$ oligomers induce cell membrane disruption have been proposed, including membrane thinning (Dante et al., 2008), excessive membrane tabulation (Pandey et al., 2011; Varkey et al., 2010), membrane extraction through amyloid-lipid co-aggregation (Hellstrand et al., 2013; Reynolds et al., 2011), and formation of ion channels to disrupt $\mathrm{Ca}^{2+}$ homeostasis 
(Arispe et al., 1993a; Shirwany et al., 2007). Membrane components can also promote the conformational change of $A \beta$ from $\alpha$-helix-rich structures to $\beta$-sheet-rich structures (Ikeda et al., 2011) and play a determining role in the uptake of $A \beta$ oligomers (Di Scala et al., 2016). Since cellular membranes are highly heterogeneous, containing many constituents, deciphering which cellular membrane components are catalyzing $A \beta$ cytotoxic action is challenging to untangle. Specifically, AD patients have much higher amounts of monosialotetrahexosylganglioside (GM1), a glycosphingolipid found in neuronal cell membranes (Yagi-Utsumi et al., 2010), than cognitively normal patients in the cerebrospinal fluid (Okada et al., 2007). GM1 clusters (Fernández-Pérez et al., 2017; Ikeda et al., 2011; Tachi et al., 2019; Yagi-Utsumi et al., 2010) are found to facilitate the $\alpha$-to- $\beta$ conformational transition of $A \beta 40$. GM1-bound $A \beta$ has been found in early pathological changes of the $A D$ brain (Kakio et al., 2002). While there is strong evidence that $A \beta$ binds to $G M 1$ and acts as a seed to further promote the formation of $A \beta$ fibrils (Yanagisawa et al., 1995), the influence of GM1 on the formation of soluble $A \beta$ oligomers, the most toxic form, and whether GM1 is involved in the pathways responsible for $A \beta$ oligomer toxicity, remains a mystery.

Here, we employ in vitro, in silico, and cellular studies to interrogate the interaction between GM1 and $A \beta$ oligomers, and to uncover the mechanisms driving the assembly and toxicity of $A \beta$ oligomers (Figure 1). We utilize liposomes, artificial vesicles $(0.05 \mu \mathrm{m}$ to $5 \mu \mathrm{m}$ in diameter (Mufamadi et al., 2011)) formed from phospholipid bilamellar membranes, to determine the interactions between $A \beta$ and lipid membranes in the presence of GM1. We find that GM1 promotes the maintenance of $A \beta$ oligomers. Using molecular dynamics simulations, we observe the interaction between $A \beta$ and GM1 and identify the most critical residue, R5, involved in the binding between $A \beta$ and GM1. We develop a fluorescence assay to interrogate the mechanism of $A \beta$ disrupting the membrane and also uncover the role of various membrane constituents on $A \beta$ aggregation. This fluorescence assay provides new evidences supporting the formation of $A \beta$ ion channels. We use mass spectrometry to characterize purified $A \beta$ oligomers formed on liposomes, and find that these membrane-associated $A \beta$ oligomers are composed of 16-21 monomers, rich in $\beta$-sheet. Finally, we perform cellular studies to demonstrate the neuronal toxicity of membraneassociated $A \beta$ oligomers. Overall, our results provide new insights into the mechanisms of $A \beta$ aggregation by revealing the role of $\mathrm{GM} 1$ in mediating early $A \beta$ oligomer formation and maintenance. Uncovering the mechanisms of $A \beta$ aggregation and determining critical cellular players responsible for downstream neurotoxicity is essential for the development of novel pharmaceutical strategies to treat $A D$.

\section{RESULTS}

GM1 liposomes promote $A \beta$ fibril formation and facilitate $A \beta$ oligomer maintenance 
GM1 clusters on liposome membrane promote the formation of $A \beta$ fibrils (Kakio et al., 2001). Do GM1 clusters promote the formation of $A \beta$ oligomers? To answer this question, we incubate $A \beta$ peptides in the presence and absence of liposomes consisting of GM1, sphingomyelin, and cholesterol (GM1 liposomes) for $0.5 \mathrm{~h}, 4 \mathrm{~h}, 24 \mathrm{~h}$, and $72 \mathrm{~h}$, respectively and then perform $10 \%$ SDS-PAGE and silver staining (Figure 2A-2D). We use cholesterol and sphingomyelin in liposomes because they are the indispensable components of GM1 clusters. We find that in the absence of GM1 liposomes, $A \beta$ oligomers of different molecular weights are formed within $0.5 \mathrm{~h}$, and the amount of $A \beta$ oligomers species then reduces with the increase of time. After $72 \mathrm{~h}$, there are nearly no $A \beta$ oligomers. We speculate that the disappeared oligomers have formed larger assemblies, such as amyloid fibrils (Figure 2E). In the presence of GM1 liposomes, we still observe abundant $A \beta$ oligomers species formed within $0.5 \mathrm{~h}$, and the amount of oligomer species reduces even more rapidly than when the $A \beta$ peptides are incubated without GM1 liposomes. However, after 72 h, we still observe a few clear $A \beta$ oligomer bands (30, 35, 40, 45, 60 kDa), indicating that some oligomers are arrested in their state, thus suggesting some distinct oligomer species from those formed without GM1. Thus, GM1 can promote the formation of fibrils by catalyzing oligomers to form fibrils, but GM1 can also facilitate the maintenance of certain oligomer species.

To interrogate if the disappeared oligomers form fibrils, we determine the formation of fibrils (Figure 2E) through thioflavin T (ThT)-binding assay; ThT is a benzthiazole dye to detect A $\mathrm{B}$ fibrils (Gade Malmos et al., 2017). We incubate $80 \mu \mathrm{M}$ A $\beta$ with ThT in the presence and absence of GM1 liposomes and find that ThT fluorescence intensities increase with time (Figure 2E), indicating that $80 \mu \mathrm{M} A \beta$ monomers incubated in the presence and absence of GM1 liposomes both aggregate into fibrils. Consistent with previous reports (Yanagisawa, 2005), we find that $A \beta$ aggregates faster and forms a greater number of aggregates in the presence of GM1 liposomes, suggesting that GM1 liposomes promote the formation of $A \beta$ fibrils. Overall, previous studies have reported that $A \beta$ binding to $G M 1$ is a seeding step to form larger aggregates (Yanagisawa et al., 1995), and our work further shows that (1) A $\beta$ oligomers form rapidly in $0.5 \mathrm{~h}$ but then partially disappear because they begin to assemble into higher molecular weight aggregates, (2) $A \beta$ fibrils form more rapidly in the presence of GM1, and (3) GM1 maintain some $A \beta$ oligomer species, probably because these species may have direct interaction with GM1. These oligomers are likely to be structurally distinct from oligomers formed on-pathway to fibrils.

To confirm the direct interaction between $A \beta$ and $G M 1$, we utilize Förster resonance energy transfer (FRET) to detect the interaction between Alexa Fluor ${ }^{\text {TM }} 555$ CTSB labeled GM1 and Alexa Fluor® 488 6E10 labeled Aß (Figure 2F). We add Alexa Fluor® 488 6E10, Alexa Fluor ${ }^{\mathrm{TM}}$ 555 CTSB, and a mixture of Alexa Fluor ${ }^{\circledR} 4886 \mathrm{E} 10$ and Alexa Fluor ${ }^{\text {TM }} 555$ CTSB to the samples of $A \beta$ incubated with GM1 liposome, respectively, to compare the fluorescence emission spectra. The fluorescence intensity peak of the donor at $518 \mathrm{~nm}$ reduces to approximately $51 \%$ of that of 
the mixture of Alexa Fluor ${ }^{\circledR} 488$ 6E10 and Alexa Fluor ${ }^{\mathrm{TM}} 555 \mathrm{CTSB}$, and combines with an increasing approximately $15 \%$ fluorescence intensity peak of the receptor at $566 \mathrm{~nm}$. The changes of the fluorescence intensity peaks are due to the non-radiative energy transfer from Alexa Fluor ${ }^{\circledR} 488$ to Alexa Fluor ${ }^{\mathrm{TM}}$ 555, suggesting an efficient FRET from A $\beta$ to GM1 liposomes membrane. Thus, we speculate that the maintenance of certain $A \beta$ oligomers species may be the result of the direct physical interaction to GM1 clusters.

In turn, $A \beta$ oligomers also impact the morphology of GM1 membranes. We use cryo-electron tomography (cryo-TEM) to analyze the morphology of liposomes incubated with or without $A \beta$. In the absence of $A \beta, G M 1$ liposomes form bilamellar vesicles with smooth surfaces (Figure $2 G \& H$ ), while in the presence of $A \beta$, GM1 liposomes become unilamellar vesicles and the membranes of these liposomes are disordered and deformed. Thus, the presence of $A \beta$ oligomers significantly affects the surface morphology of GM1 liposome membranes by deforming the membranes. We posit that for neurons, $A \beta$ may interact with GM1 clusters in cell membranes (Bhowmik et al., 2015; Jang et al., 2007, 2010; Quist et al., 2005) in a similar fashion in the brain, thereby resulting in deformed membrane and, ultimately, in neurotoxicity and synaptic loss (Du et al., 2019).

\section{R5 of $A \beta 42$ plays an important role in the interaction of $A \beta$ and GM1 membranes}

We perform 100 ns molecular dynamics (MD) simulations of GM1 membrane and 5 Aß42 monomers (Figure $3 A$ ). We calculate the minimum distance between atoms of each residue of $A \beta$ and all atoms of GM1 on the membrane. We find that the fifth residue (arginine, R5) of $A \beta$ maintains a distance of 1-2 ̊ from GM1 (Figure 3C\&D), suggesting that R5 stably binds GM1. Thus, we posit that $R 5$ plays a critical role in the interaction between $A \beta$ and $G M 1$, specifically, the guanidine group in R5 interacting with the $\mathrm{O} 11$ and $\mathrm{O} 12$ atoms in GM1 (Figure 3B). We further computationally substitute R5 to glycine, and upon performing MD simulations we find that the average distance between G5 and GM1 increases to $>10 \AA$ (Figure 3E) and is within binding distance $(<2 \AA)$ for as little as $2 \%$ of the time (Figure $3 F$ ), indicating that the mutation of R5G disrupts the tight binding interaction between the fifth residue and GM1. This result strongly suggests the critical role of R5 in GM1-A $\beta$ interaction.

To confirm the role of R5 experimentally, we substitute arginine with glycine and then utilize FRET to detect the interaction between the mutant $A \beta$ and GM1 membrane (Figure $3 G$ ). The fluorescence intensity peak of the acceptor at $566 \mathrm{~nm}$ of the mixture of Alexa Fluor ${ }^{\circledR} 4886 \mathrm{E} 10$ and Alexa FluorTM 555 CTSB is similar to that of the sample containing only the acceptor. In contrast to wild type $A \beta$ (Figure $2 \mathrm{~F}$ ), there is no energy transfer from donor to acceptor for the mutant $A \beta$, indicating that the mutant $A \beta$ does not bind to the GM1 liposome membrane. To determine the effect of the mutation on the formation of fibrils, we perform the ThT-based fibril detection assay for the mutants. We find that R5G aggregates into fibrils in $100 \mathrm{~min}$, then the fibrils slowly dissociate (Figure $3 \mathrm{H} \& \mathrm{I}$ ). In comparison, the wild type $A \beta$ fibrils do not dissociate 
(Figure 2E). This observation suggests that $\mathrm{R} 5$ also plays an important role in A $\beta$ fibril stability. Finally, we find that compared to HEPES buffer, the presence of GM1 liposomes inhibits aggregation of the mutant $A \beta$ into fibrils, as the sample with GM1 liposomes always feature a lower ThT fluorescence intensity.

\section{GM1-catalyzed channel formation by $A \beta$ oligomers}

Various mechanisms (Dante et al., 2008; Hellstrand et al., 2013; Pandey et al., 2011; Reynolds et al., 2011; Varkey et al., 2010) by which $A \beta$ oligomers disrupt cell membranes have been proposed. Our work strongly supports the ion channel hypothesis (Kagan et al., 2002) that posits that $A \beta$ oligomers damage neuron by forming ion channels channels (Arispe et al., 1993a; Shirwany et al., 2007). Although the hypothesis provides a biophysical mechanism for explaining the $A \beta$ oligomers toxicity(Hane and Leonenko, 2014), it needs further validation. We develop a fluorescence assay to interrogate if the $A \beta$ oligomers maintained by GM1 form ion channels to disrupt the plasma membrane, with the goal of uncovering the role of various membrane constituents (PC, SM, and GM1) in the disruption process. We encapsulate $\mathrm{Ca}^{2+}$ inside liposomes and dialyze away the excess $\mathrm{Ca}^{2+}$ from outside of the liposomes. In support of the ion channel hypothesis, we expect that the formation of $A \beta$ ion channels would lead to the efflux of $\mathrm{Ca}^{2+}$, thus resulting in an increase of $\mathrm{Ca}^{2+}$ concentration outside the liposomes. We utilize a calcium sensitive dye (Fluo-4) to detect the $\mathrm{Ca}^{2+}$ concentration change outside of the liposomes. To verify whether we successfully encapsulated $\mathrm{Ca}^{2+}$ inside the liposomes, we add Triton $\mathrm{X}-100$ to lyse the $\mathrm{Ca}^{2+}$-loaded liposomes (Supplementary Figure 1). We prepare two types of liposomes: (1) PC liposomes (L-a-Phosphatidylcholine+ sphingomyelin +cholesterol), and (2) GM1 liposomes (GM1+ sphingomyelin +cholesterol). We observe $\mathrm{Ca}^{2+}$ efflux after adding Triton $\mathrm{X}-100$ (Supplementary Figure 1), confirming that $\mathrm{Ca}^{2+}$ is successfully encapsulated inside the liposomes. We incubate varying concentrations of $A \beta$ with $\mathrm{Ca}^{2+}$-encapsulated $\mathrm{GM} 1$ and $\mathrm{PC}$ liposomes. When $A \beta$ concentration is higher than $10 \mu \mathrm{M}, \mathrm{GM} 1$ and $\mathrm{PC}$ liposomes have similar $\mathrm{Ca}^{2+}$ efflux, reflecting similar disruption to liposomes, yet when $A \beta$ concentration is lower than $1 \mu \mathrm{M}, \mathrm{GM} 1$ liposomes have much more $\mathrm{Ca}^{2+}$ efflux than that of $\mathrm{PC}$ liposomes, indicating that $\mathrm{GM} 1$ liposomes are disrupted to a greater extent. (Figure 4A\&B). Thus, at high $A \beta$ concentration $(>10 \mu M), A \beta$ induces leakage of both liposome types; at low $A \beta$ concentrations, $A \beta$ induces more leakage of GM1 liposomes than that of PC liposomes, indicating that GM1 is key to the process of $A \beta$ induced membrane disruption and may serve as a catalyst to promote disruption especially at low $A \beta$ concentrations $(<1 \mu \mathrm{M})$. To further demonstrate that $\mathrm{PC}$ and cholesterol are irrelevant to $\mathrm{Ca}^{2+}$ efflux, we also test three more types of PC liposomes with different composition proportion of PC, cholesterol, and sphingomyelin (20\% PC, 40\% cholesterol, 40\% sphingomyelin; $40 \%$ PC, $20 \%$ cholesterol, 40\% sphingomyelin; 50\% PC, 10\% cholesterol, 40\% sphingomyelin;). We encapsulate $\mathrm{Ca}^{2+}$ inside these liposomes and incubate them with $\mathrm{A}$. We find no significant $\mathrm{Ca}^{2+}$ 
efflux (Supplementary Figure 2), indicating no $A \beta$-induced membrane disruption.

We observe greater $\mathrm{Ca}^{2+}$ efflux in liposomes incubated with $A \beta$ as compared to liposomes incubated without $A \beta$, suggesting that $\mathrm{Ca}^{2+}$ exits liposomes through two potential mechanisms: (i) $A \beta$ forms channels on liposome membranes through which calcium can pass, or (ii) $A \beta$ disrupts the integrity of the liposome membranes. To validate the formation of $A \beta$ ion channels, we encapsulate Fluo-4 inside liposomes (Figure 4C\&D) and incubate the liposomes with $A \beta$ for 3 days. Next, we add extracellular $\mathrm{Ca}^{2+}$, incubate for another $3 \mathrm{~h}$, and add an excess of ethylenediaminetetraacetic acid (EDTA) to chelate the $\mathrm{Ca}^{2+}$ outside the liposomes. EDTA has a higher binding affinity to $\mathrm{Ca}^{2+}$ than Fluo-4 (Park and Palmer, 2015). If $A \beta$ disrupts the liposomes, the encapsulated Fluo-4 dye will diffuse to the solution outside of the liposomes, where it will be inert because all extracellular $\mathrm{Ca}^{2+}$ have been chelated by EDTA. Conversely, if ion channels are formed in the liposome membranes, $\mathrm{Ca}^{2+}$ will enter the liposomes through the channels to interact with Fluo-4 and emit fluorescent signals. Importantly, EDTA is too large to enter the liposomes through the ion channels. Indeed, we observe calcium influx, suggesting that $A \beta$ forms ion channels capable of passing $\mathrm{Ca}^{2+}$ ions. Hence, we find that $A \beta$ may form ion channels either spontaneously at high concentrations $(\sim 10 \mu \mathrm{M})$ or with $\mathrm{GM} 1$ as a catalyst at low concentration $(\sim 100 \mathrm{nM})$.

\section{Structural characterization of $A \beta$ oligomers formed on membranes}

To determine the size of $A \beta$ oligomer species that can form channels, we utilize photo induced cross-linking of unmodified proteins (Fancy and Kodadek, 1999) (PICUP, Supplementary Figure 3) to cross-link $A \beta$ oligomers and then remove $A \beta$ oligomers from the solution using $1000 \mathrm{kDa}$ MWCO centrifugation tube, so that only $A \beta$ oligomers on the membrane are retained. We determine the molecular weight of the membrane-bound oligomers by mass spectrometry (MS) (Figure 5A\&B). During PICUP, the formation of a cross-linking bond reduces the molecular weight by $2.016 \mathrm{Da}$, the mass of two hydrogens. We observe four possible molecular weights 18028.4 , 72196, 85711.3, and 94711.9 Da, corresponding to 4, 16, 19, and $21 \mathrm{~A} \beta$ monomers with 14, 14, 27 , and 41 cross-linkers, respectively. To determine the most probable number of monomers in $A \beta$ oligomers that can form channels, we divide the oligomer samples into 4 parts according to the molecular weight: $<25 \mathrm{kDa}, 25-45 \mathrm{kDa}, 45-100 \mathrm{kDa}$, and $>100 \mathrm{kDa}$. We then incubate these four different $A \beta$ samples with $\mathrm{Ca}^{2+}$-encapsulated liposomes and measure the fluorescence intensity, as described previously. The 45-100 kDa sample has the highest fluorescence intensity, indicating that the most likely molecular weight range of $A \beta$ oligomers that can form channels is 45-100 kDa (Figure $5 \mathrm{C}$ ), which may consist of 16, 19, or $21 \mathrm{~A} \beta$ monomers.

We further determine the secondary structure of $A \beta$ oligomers by circular dichroism (CD) and use BeStSel(Micsonai et al., 2018) to analyze the CD data in favor with its better estimation of $\beta$ sheet content. We prepare two oligomer samples, one obtained from the liposome membrane 
(membrane $A \beta$ oligomers) and the other from the buffer solution (solution $A \beta$ oligomers) (Figure $5 \mathrm{D} \& \mathrm{E})$. Solution $A \beta$ oligomers have $6.4 \%$ helices, $31.1 \%$ antiparallel beta-sheets, $16.4 \%$ turns, and $46.2 \%$ other structures, while membrane $A \beta$ oligomers have a significantly higher percentage (56.8\%) of antiparallel beta-sheet structures. Consistent with previous reports (Devarajan and Sharmila, 2014; Matsuzaki, 2014; Okada et al., 2007), our results show that GM1 membrane can promote a conformational change of oligomeric $A \beta$ to form $\beta$-sheet-rich structures.

We compare the structural features of $A \beta$ oligomers and fibrils by digesting all purified $A \beta$ oligomers and fibrils with pepsin, and measuring the abundance of fragments by mass spectrometry (Proctor et al.) (Figure 5F\&G). Theoretically, higher abundant peptides are likely to appear on the surface of the protein because surface residues have a higher chance to be digested, while lower abundant peptides are buried inside the structure (Proctor et al.). In both membrane $A \beta$ fibrils and solution $A \beta$ fibrils, the abundances of $A \beta_{4-19}$ peptides are high, suggesting that they are on the surface; the abundances of $A \beta_{36-42}$ peptides are low, suggesting that they are internal. Regardless of the presence or absence of GM1 liposomes, the abundances of peptides of the two fibrils are similar, indicating that although GM1 liposomes promote the formation of fibrils, they do not affect the structure of fibrils. However, the peptide abundances of the solution $A \beta$ oligomers and membrane $A \beta$ oligomers are drastically different. In membrane $A \beta$ oligomers, $A \beta_{20-34}$ peptides feature high abundances, while $A \beta_{1-17}$ peptides feature low abundances. In solution $A \beta$ oligomers, $A \beta_{4-19}$ peptides have the highest abundances, and $A \beta_{35-42}$ peptides have the lower abundances. Thus, the structures of membrane $A \beta$ oligomers, promoted by GM1 liposomes, are distinct from the structures of solution $A \beta$ oligomers. Finally, based on the abundances of peptides, the structures of $A \beta$ oligomers and fibrils are also drastically different. Overall, the presence of GM1 liposomes changes $A \beta$ oligomer structures but does not change $A \beta$ fibril structures.

\section{Toxicity of $A \beta$ oligomers in vitro}

We interrogate the toxicity of these GM1-bound $A \beta$ oligomers by cellular studies (Figure $6 A$ ). We incubate $A \beta$ with GM1 liposomes, crosslink them, and remove solution $A \beta$ oligomers. We then add the retained membrane $A \beta$ oligomers to differentiated PC12 cells. We incubate $A \beta$ with the cells for 3 days and then measure the toxicity by calcein AM and ethidium homodimer-1 live/dead viability assay. Membrane $A \beta$ oligomers at the concentration of $5 \mu \mathrm{M}$ exhibit toxicity (increased dead/live cells ratio) in PC12 cells (Figure 6B\&C). While at the same concentration, solution $A \beta$ oligomers do not exhibit toxicity (Supplementary Figure 4). Addition of membrane A $\beta$ oligomers induces increased levels of cleaved caspase-3 compared to the live control (Supplementary Figure 5). The toxicity of membrane $A \beta$ oligomers is consistent with our fluorescence results (Figure 4): the increase of $A \beta$ oligomer concentration leads to the increase of $\mathrm{Ca}^{2+}$ efflux caused by membrane disruption, suggesting that the toxicity of membrane $A \beta$ oligomers may be related 
to the dysregulation of calcium homeostasis.

Numerous GM1 gangliosides are present in the membrane of the differentiated PC 12 cell line (Nishio et al., 2004). To interrogate if membrane $A \beta$ oligomers incur toxicity for cells with low GM1 content, we perform a viability assay using post-natal day 1 (P1) CD1 mouse cortical neurons, which have less GM1 since the amount of GM1 in the mouse brain has been previously reported to be minimal at birth, increasing with age (Yamamoto et al., 2008). Upon repeating the previously-described Fluo-4 assay in these primary neurons, we find that membrane $A \beta$ oligomers do not result in calcium efflux (Supplementary Figure 6). The lack of effect on primary neurons, which are notoriously less robust than cell lines, suggests that the lack of GM1 in the cell membranes of the neonate-derived primary cells protects them from being compromised by $A \beta$ oligomers, further supporting that GM1 is critically necessary for the toxicity of $A \beta$ oligomers.

\section{DISCUSSION}

The concentration of $A \beta$ is important to the formation of oligomers (Hu et al., 2009; Thal et al., 2015). Most in vitro aggregation studies and $A \beta$ ion channel studies have been conducted with $A \beta$ peptide concentrations exceeding physiological concentrations by more than 1000 -fold. Such a stark disparity between in vitro and physiological $A \beta$ concentrations required for aggregation suggests the presence of an aggregation catalyst in living cells (Luo et al., 2013; Mantyh et al., 1993). Hence, the mechanism of oligomer formation at physiological concentrations remains one of the biggest mysteries of $A D$. Previous studies have demonstrated the destructive effects of $A \beta$ on membranes with $A \beta$ concentrations much higher than the physiological concentration (Chi et al., 2007). Here we demonstrate that phospholipid bilayer membranes can be disrupted by $A \beta$ at nanomolar concentrations with GM1 serving as the catalyst.

GM1 is distributed as clusters on neuronal membranes in the mouse brain (Matsuzaki, 2014), and the binding of $A \beta$ to GM1 clusters may increase the local concentration of $A \beta$ and cause a conformational change that promotes aggregation (Fernández-Pérez et al., 2017; Ikeda et al., 2011; Yagi-Utsumi et al., 2010). The presence of GM1 clusters aiding the maintenance of $A \beta$ oligomers may be due to the high binding affinity between GM1 clusters and $A \beta$. Previous reports and our results both suggest that GM1 can bind to $A \beta$ (Kakio et al., 2002) and promote the formation of $A \beta$ fibrils (Yanagisawa et al., 1995), and we further find that some $A \beta$ oligomer species are stable and not inclined to further aggregate to fibrils in the presence of GM1 (Supplementary Figure 5). Our liposome encapsulation experiments demonstrate that these stable oligomers may form channel-like structures, which provides new evidences for the hypothesis that $A \beta$ forms channel-like oligomeric structures that disrupt cellular calcium homeostasis (Jang et al., 2010). The formation of channel-like structures may be contributed by the conformational change of $A \beta$ to $\beta$-sheet-rich states, which has been demonstrated in both previous studies (Chen et al., 2017; Matsuzaki, 2014) and our results. Thus, the mechanism of 
the disrupted calcium homeostasis may be that GM1 catalyzes the formation of $A \beta$ ion channels thereby decreasing the calcium gradient (Ledeen and $\mathrm{Wu}, 2015)$. Furthermore, although some studies (Arispe et al., 1993b, 1993a; Jang et al., 2010) have utilized channel conductance measurements on planar lipid bilamellar membranes to suggest that $A \beta$ forms ion channels, the size and structure information of the channel oligomers were unclear. In our work, we utilize mass spectrometry and $C D$ to measure the possible size and secondary structure of $A \beta$ oligomers, and we also find that the binding of $A \beta$ to the GM1 membrane deforms the GM1 membrane.

Overall, we integrate computational, biochemical, and cellular studies to uncover the molecular etiology of $A \beta$ aggregation modulated by $G M 1$ in $A D$ pathology and identify processes responsible for neuronal toxicity. Such a comprehensive approach is necessary to decouple multiple processes accompanying AD pathophysiology.

\section{METHODS}

\section{Preparation of liposomes}

We dissolve GM1 (Sigma-Aldrich), L-a-Phosphatidylcholine (PC, Sigma-Aldrich), sphingomyelin (VWR International), and cholesterol (Fisher Scientific) in a chloroform/methanol (1:1, v/v) mixture at a total concentration of $1 \mathrm{mM}$. To mimic the GM1 cluster on the cell membrane, the molar ratio of GM1, sphingomyelin, and cholesterol is 1:2:2 for GM1 liposomes. For PC liposomes, the molar ratio of PC, sphingomyelin, and cholesterol is 1:2:2. To prepare liposomes, we first dry the organic solvents under a gentle stream of nitrogen for $2 \mathrm{~h}$ and then under vacuum overnight. Then, we rehydrate the resulting lipid film with HEPES buffer (10mM HEPES and $150 \mathrm{mM} \mathrm{NaCl}$, $\mathrm{pH} 7.4$ ), and incubate $1 \mathrm{~h}$ at $45^{\circ} \mathrm{C}$ water bath, vortexing every $15 \mathrm{~min}$. In order to prepare $\mathrm{Ca}^{2+}$ encapsulated liposomes, we replace the rehydrated lipid HEPES buffer with $10 \mathrm{mM} \mathrm{CaCl}_{2}$ (Fisher Scientific), 10mM HEPES, and $140 \mathrm{mM} \mathrm{NaCl}$, pH 7.4 (Colletier et al., 2002; Sanghera et al., 2011). To prepare dye-encapsulated liposomes, we replace the rehydrated lipid buffer with 0.03 mM Fluo-4 (Life Technologies), HEPES buffer. The dye-encapsulated liposomes are protected from light at all times. We sonicate the rehydrated suspension for $15 \mathrm{~min}$, and then freeze-thaw for 5 cycles in the liquid nitrogen and $60^{\circ} \mathrm{C}$ water bath. To obtain uniform liposomes, we extrude the resulting suspension 16 times with an Avanti extruder. To encapsulate calcium and dye, we use $800 \mathrm{~nm}$ pore size polycarbonate filters to filter the liposomes. For the $\mathrm{Ca}^{2+}$-encapsulated and dye-encapsulated liposomes, we use $10000 \mathrm{Da}$ molecular weight cut off (MWCO) dialysis cassette with HEPES buffer changed 3 times a day to remove the $\mathrm{Ca}^{2+}$ and dye in the buffer outside the liposomes.

\section{Fluorescence intensity determination}


We dissolve AB42 (Fisher Scientific) in DMSO at a concentration of $1 \mathrm{mM}$ and sonicate for $10 \mathrm{~min}$. For the $\mathrm{Ca}^{2+}$-encapsulated liposomes, we add different concentrations (100 nM, $500 \mathrm{nM}, 1 \mu \mathrm{M}, 10$ $\mu \mathrm{M}, 20 \mu \mathrm{M}, 30 \mu \mathrm{M})$ of $\mathrm{A} \beta 42$ and incubate with liposomes for 3 days at room temperature. We add $50 \mu \mathrm{M}$ Fluo-4 into the incubated A 342 and liposomes solution, and determine the fluorescence intensity using a SpectraMax i3 plate reader. We treat control sample in the same way, except without added $A \beta 42$. We analyze the fluorescence intensity ratio of samples incubated with different concentrations of $A \beta 42$ and control.

We protect the dye-encapsulated liposomes from light throughout the experiment to prevent photo-bleaching. We add different concentrations of $\mathrm{A} \beta 42(500 \mathrm{nM}, 1 \mu \mathrm{M}, 5 \mu \mathrm{M}, 10 \mu \mathrm{M})$ into the liposome solutions and incubate for 3 days at room temperature. We add $14 \mathrm{mM} \mathrm{CaCl}_{2}$ into the incubated $A \beta 42$ and liposomes and incubate for $1 \mathrm{~h}$ to ensure that calcium ions have enough time to enter the liposomes through the ion channels. Then, we add $16.5 \mathrm{mM}$ EDTA (excess) to bind all the $\mathrm{Ca}^{2+}$ in the solution. In this way, only the $\mathrm{Ca}^{2+}$ that enters the liposomes can bind with Fluo-4. Similarly, we treat control sample in the same way, except without adding A $\beta 42$. Finally, we determine the fluorescence intensity using a SpectraMax i3 plate reader. After incubation with GM1 liposomes, Aß42 oligomers were divided into >100, 45-100, 25-45, and <25 kDa samples according to a trident pre-stained protein ladder (GTX50875) and then the same concentration and volume resulted sample was incubated with $\mathrm{Ca}^{2+}$-encapsulated GM1 liposomes overnight. After that, the fluorescence intensity was determined, as previously mentioned.

\section{Förster Resonance Energy Transfer (FRET)}

We incubate $10 \mu \mathrm{M}$ wild type or mutant $A \beta 42$ with $200 \mu \mathrm{L}$ GM1 liposomes for 3 days. After that, we add $10 \mu \mathrm{g} / \mathrm{mL}$ Alexa Fluor® 488 anti- $\beta$-Amyloid, 1-16 Antibody (6E10, Biolegend) to the incubated liposome solution to label $A \beta 42$ as the donor, and $10 \mu \mathrm{g} / \mathrm{mL}$ Cholera Toxin Subunit B (Recombinant) Alexa FluorTM 555 Conjugate (CTSB, Fisher Scientific) to label GM1 as the acceptor. We incubate Alexa Fluor ${ }^{\circledR} 488$ 6E10 and Alexa Fluor ${ }^{\text {TM }} 555$ CTSB with liposome solution for $1 \mathrm{~h}$ at room temperature. To remove the Alexa Fluor ${ }^{\circledR} 488$ 6E10 and Alexa Fluor ${ }^{\mathrm{TM}}$ 555 CTSB that did not bind to A $\beta$ and GM1 liposomes, we use $1000 \mathrm{kDa}$ MWCO centrifugation tube at $1000 \mathrm{rpm}$ and dilute samples 1:40 in HEPES buffer. and centrifuge to the final volume of $50 \mu \mathrm{L}$ and repeat this process. We use SpectraMax i3 to analyze the labeled sample. The excitation wavelength is $492 \mathrm{~nm}$ with $2 \mathrm{~nm}$ slit width. We collect the emission spectra from 518 to $750 \mathrm{~nm}$. For the donor control, we treat sample in the same way except we do not add the acceptor (Alexa Fluor TM 555 CTSB) to label GM1. For the acceptor control, we treat sample in the same way except without Alexa Fluor® 4886 E10 to label A 3.

Fluorescence characteristics of $A \beta$ fibrils using Thioflavin $T$ (ThT) 
We determine the effect of GM1 liposomes on A $\beta$ aggregation using ThT (VWR International). We incubate $80 \mu \mathrm{M}$ wild type or mutant $A \beta$ monomers in the presence or absence of GM1 liposomes containing $10 \mu \mathrm{M}$ ThT at $37{ }^{\circ} \mathrm{C}$ shaking in black 96-well plates with seal. We treat HEPES buffer containing $10 \mu \mathrm{M}$ ThT in the presence and absence of GM1 as control. We collect the fluorescence intensities of all samples every 30 seconds for 3 days using a SpectraMax i3 plate reader with excitation wavelength of $445 \mathrm{~nm}$ and emission wavelength of $490 \mathrm{~nm}$.

\section{Cross-linking}

To obtain stable $A \beta$ oligomers, particularly the $A \beta$ oligomers formed on membranes, we utilize the photo-induced cross-linking of unmodified proteins (PICUP) method (Bitan and Teplow, 2004) to cross-link. We add ammonium persulfate (APS $1 \mathrm{mM}, 10 \mu \mathrm{L}$, Dot Scientific) and Tris (2,2bipyridyl)dichlororuthenium(II) hexahydrate (Ru(II)Bpy ${ }^{2+} 0.05 \mathrm{mM}, 10 \mu \mathrm{L}$, Sigma-Aldrich) in 10 mM HEPES ( $\mathrm{pH} 7.4)$ to the incubated $A \beta$ oligomer solution $(180 \mu \mathrm{L})$. We irradiate the resulting solution with a $500 \mathrm{~W}$ lamp for 5 seconds and quench the cross-linking process with $47.6 \mathrm{mM}$ dithiothreitol (DTT 1M, $10 \mu \mathrm{L}$, Dot Scientific).

\section{Analysis of the size of $A \beta$ oligomers by SDS-PAGE and silver staining}

We incubate $A \beta$ in the presence or absence of GM1 liposomes and analyze samples at $0.5 \mathrm{~h}, 4 \mathrm{~h}$, $24 \mathrm{~h}$, and $72 \mathrm{~h}$. We cross-link all samples using the PICUP method. For the sample in the presence of GM1 liposomes, we add $40 \mu \mathrm{M}$ N-octylglucoside (Dot Scientific) into the samples and then incubate at room temperature for $1 \mathrm{~h}$ to dissolve the lipids of the liposomes. We add leammli SDS sample buffer dye (Fisher Scientific) to the resulting solution and heat at $95^{\circ} \mathrm{C}$ for 10 min. We use $10 \%$ SDS-PADE and silver staining (Fisher Scientific) to analyze the formed A $\beta$ oligomers.

\section{Purification of $A \beta 42$ oligomers on the liposomes}

We incubate $A \beta 42$ monomers with GM1 liposomes at room temperature for 3 days and cross-link $A \beta$ before further purification. We use $1000 \mathrm{kDa}$ MWCO centrifugation tubes, spun at $1300 \mathrm{rpm}$, to remove $A \beta$ oligomers that did not insert into liposomes. We treat sample with $\mathrm{N}$-octylglucoside, leammli SDS sample buffer dye, heater, SDS-PAGE, and silver staining as described above. After gel electrophoresis, we cut out the gel portion according to the reference results of silver staining. We crush the cut gel portion containing the $A \beta$ oligomers of interested and dissolve them in HEPES buffer overnight in a shaker at $4^{\circ} \mathrm{C}$. We centrifuge the resulting samples at 10000 $\mathrm{g}$ for $10 \mathrm{~min}$ and save the supernatants for further concentration by centrifugation. To measure the size of the $A \beta$ channels, we cut the gel according to various molecular weight ranges $(>100$, $45-100,25-45,<25 \mathrm{kDa}$ ) and purify $A \beta$ oligomers in the gel as described above. We determine the concentration of purified $A \beta$ sample using Nanodrop and a bicinchoninic acid (BCA) protein assay kit. 


\section{Secondary structure}

We incubate $A \beta 42$ monomers $(10 \mu \mathrm{M})$ for 3 days at room temperature in the presence or absence of GM1 liposomes, and then cross-link samples using PICUP. For the sample of Aß42 incubated in the presence of GM1 liposomes, we remove $A \beta$ oligomers in the solution and add $\mathrm{N}$ octylglucoside to dissolve the lipids as described previously as mentioned previously. We remove the fibrils in the resulting solution using $1000 \mathrm{kDa}$ MWCO centrifugation tubes spun at $3900 \mathrm{rpm}$, and wash with HEPES buffer. We remove the monomers, dimers, and lipids using $10 \mathrm{kDa}$ MWCO centrifugation tubes, spun at $3900 \mathrm{rpm}$, and wash with HEPES buffer with $40 \mu \mathrm{M} \mathrm{N}$ octylglucoside and then wash again with HEPES buffer. For the control sample of $A \beta 42$ monomers $(10 \mu \mathrm{M})$ incubated in HEPES without liposomes, we remove the fibrils, monomers, and dimers in the same way except adding $\mathrm{N}$-octylglucoside to dissolve the lipids and washing with $40 \mu \mathrm{M} N$-octylglucoside HEPES buffer. We determine the concentration of $A \beta$ oligomers using BCA protein assay kit. We determine the secondary structure characteristics of $A \beta 42$ channels and oligomers using a Jasco J-1500 circular dichroism spectrophotometer. We place samples in $0.1-\mathrm{mm}$ path-length $(200 \mathrm{uL})$ cuvettes, and record the spectra range at $185-240 \mathrm{~nm}$ with $0.5 \mathrm{~nm}$ data pitch and scanning speed of $50 \mathrm{~nm} / \mathrm{min}$. We scan each sample three times and calculate average. We use the software BESTSEL(Micsonai et al., 2018) to analyze experimental data and get the fractional content of the helix, sheet, turn, and other structures element.

\section{PC-12 cell culture}

We obtain PC-12 cells from the American Type Culture Collection (ATCC). For the PC-12 cells, we use DMEM (VWR International) supplemented with 5\% heat inactivated horse serum (Life Technologies), $5 \%$ fetal bovine serum (Fisher Scientific), and 1\% Penicillin/Streptomycin (Fisher Scientific). We culture cells at $37^{\circ} \mathrm{C}$ with $5 \% \mathrm{CO}_{2}$. For the neuronal differentiation, we seed PC-12 cells in 96-well plates at 2000 cells/well. Prior to seeding, we treat the 96-well plate by UVOcleaner (Jelight Company, model 18) for $30 \mathrm{~min}$, coat with 10X diluted collagen and incubate at $4^{\circ} \mathrm{C}$ for $2 \mathrm{~h}$ before used. For the differentiated PC-12 cells, we use DMEM supplemented with $1 \%$ heat inactivated horse serum, $1 \%$ Penicillin/Streptomycin, and $100 \mathrm{ng} / \mathrm{mL}$ nerve growth factor (Sigma Aldrich) and culture for 1 week at $37^{\circ} \mathrm{C}$ with $5 \% \mathrm{CO}_{2}$. Before further analysis, we confirm differentiation by visual observation using a phase contrast microscope.

\section{Cell viability assay}

We determine cell viability using calcein $\mathrm{AM}$ and ethidium homodimer-1 dye. After differentiation, we add purified $A \beta$ oligomers samples to the differentiation cells and incubate for 3 days. For the dead cell controls, we add $70 \%$ methanol to cells $2 \mathrm{~h}$ before plate read. We remove the differentiation medium and wash the cells twice with PBS. For each well, we add $4 \mu \mathrm{M}$ ethidium homodimer-1 and $2 \mu \mathrm{M}$ calcein AM in PBS to label live and dead cells. Cells then incubate for 30 
min at room temperature. We determine the fluorescence intensity by SpectraMax i3. For calcein $\mathrm{AM}$, the excitation wavelength is $495 \mathrm{~nm}$ and the emission wavelength is $525 \mathrm{~nm}$. For ethidium homodimer-1, the excitation wavelength is $495 \mathrm{~nm}$ and the emission wavelength is $645 \mathrm{~nm}$. We take the fluorescent images on a Keyence Bz-x800 fluorescent microscope.

\section{Western blot}

We incubate the differentiated PC-12 cells in the presence and absence of purified A $\beta$ oligomer samples for 3 days and then lyse with ice-cold RIPA buffer (PBS, 1\% Nonidet P-40, 0.5\% sodium deoxycholate, $0.1 \% \mathrm{SDS}$ ). We then collect the lysed solution for Western blot. After homogenization, we centrifuge cell samples at $12000 \mathrm{rpm}$ for $20 \mathrm{~min}$ and collect the supernatants. We add $2 X$ SDS sample buffer into the supernatant solutions and heat samples at $95{ }^{\circ} \mathrm{C}$ for 10 min. We separate the samples on a $12 \%$ polyacrylamide gel then transfer to a PVDF membrane with transfer buffer (25mM Tris, 192mM Glycine, $0.1 \%$ SDS,20\% Methanol, $\mathrm{pH} 8.3$ ) at $80 \mathrm{~V}$ for 90 min at $4^{\circ} \mathrm{C}$. We block the blots with 5\% BSA in TBST (10 mM Tris- $\mathrm{HCl}, \mathrm{pH} 7.6,150 \mathrm{mM} \mathrm{NaCl}, 0.1 \%$ Tween-20) for $1 \mathrm{~h}$ at room temperature, then incubate with anti-Caspase 3 (Sigma AB3623) and anti-Vinculin (Sigma SAB4200729), diluted 1:100 and 1:1000, respectively, in blocking buffer (caspase-3 and vinculin) overnight at $4^{\circ} \mathrm{C}$. After washing 3 times with TBST, we incubate the membrane in anti-Mouse $\operatorname{lgG}$ conjugated with horseradish peroxidase for $3 \mathrm{hr}$ at room temperature. Before film imaging, we wash the blot 3 times with TBST and soak for 5 min in chemiluminescent substrate (Thermo Scientific catalog \# 34080).

\section{Mass Spectrometry (MS)}

After cross-linking and purification, we measure the molecular weight of the $A \beta$ oligomers with MS using the Sciex 5600 triple tof (AB SCIEX). Then, we digest purified $A \beta$ oligomers and fibrils with pepsin. We add $1 \mathrm{~N} \mathrm{HCl}$ to the $A \beta$ samples to a final concentration of $0.04 \mathrm{~N}$ and suspend pepsin in $100 \mathrm{mM}$ acetate buffer $(\mathrm{pH} 3.5)$. We add the pepsin to $A \beta$ solution as the ratio of 1:20 (enzyme:protein $\mathrm{W}: \mathrm{W}$ ) and incubate them for $1 \mathrm{~h}$ at $37^{\circ} \mathrm{C}$. We add $1 \mathrm{M}$ Tris buffer $(\mathrm{pH} 8)$ to a final concentration of $150 \mathrm{mM}$ to stop the reaction. And then we determine the resulting peptides with Sciex 5600 triple tof (AB SCIEX) and analyze them using the ProteinPilot software.

\section{Cryo Electron Tomography}

To increase the ratio of $A \beta$ :lipid to 1:10, we dilute GM1 liposomes 10 times and incubate the resulting GM1 liposomes with or without $10 \mu \mathrm{M} A \beta$ for 3 days. Then, we concentrate the samples using a $100 \mathrm{kDa}$ MWCO centrifuge tube, centrifuging at $1300 \mathrm{rpm}$ to reduce sample volume from $1 \mathrm{~mL}$ to $50 \mu \mathrm{L}$ to increase the concentration of liposomes. We mix the samples with $10 \mathrm{~nm}$ gold fiducials before pipetting $4 \mu$ l onto a freshly glow-discharged Quantifoil R2/2 holey carbon grid. We hand grids blotted from behind and plunge grids into liquid ethane using a Mark IV Vitrobot (Thermo Fisher Scientific) for vitrification. We then transfer samples under liquid nitrogen into a 
Titan Krios G3i cryo TEM (Thermo Fisher Scientific) operating at $300 \mathrm{kV}$ for the acquisition of tilt series. We target holes containing liposomes contained within vitreous ice data collection and collect tilt series in $2^{\circ}$ increments from $-60^{\circ}$ to $+60^{\circ}$ at $-6.0 \mu \mathrm{m}$ defocus. Tilt series images are acquired with a Bioquantum energy filter (Gatan) operating at the zero-loss peak using a K3 direct electron detector (Gatan) in single electron counting mode. We use a nominal magnification of $\times 33,000$ which correspond to a pixel size of $3.3 \mathrm{~A} \square /$ pixel. We set exposure time to achieve a total electron dose of $\sim 120 \mathrm{e}^{-} / \mathrm{A} \square^{2}$ for a complete tilt series. We collect six to ten tilt series from each grid. We reconstruct tomograms using the IMOD(Kremer et al., 1996) software suite.

\section{Computational modeling}

We first model the GM1 membrane structure through CharmmGUI (Jo et al., 2008) with the ratio of SM, Cholesterol, GM1 as 4:4:2. We then model the intact structure of $A \beta$ using SwissModel (Schwede et al., 2003) with PDB ID 1IYT as the template. The missing residues in the N-terminal region are completed by SwissModel. Next, we perform molecular dynamics simulation of the GM1 membrane-A system using GROMACS (Van Der Spoel et al., 2005). The Charmm36m (Huang et al., 2017) force field for the protein and lipid parameters are used. Hydrogens for heavy atoms were added by the pdb2gmx module in the GROMACS simulation package. The system is subsequently energy-minimized for 2000 steps using the conjugate gradient algorithm, and another 2000 steps using the steepest descent algorithm. The structure is solvated using explicit water in a cubic periodic box with water molecules extending $10 \AA$ outside the protein on all sides. Water molecules are described using a simple point charge water model. The system is solvated using TIP3 water molecules, then energy-minimized again and heated up gradually to reach a temperature of $310 \mathrm{~K}$ using a V-rescale thermostat with a coupling constant of $0.1 \mathrm{ps}$. The solvent density is adjusted under isobaric and isothermal conditions at 1 bar and $310 \mathrm{~K}$. A ParrinelloRahman barostat with isotropic pressure coupling and a coupling constant of 0.1 ps was used to set the pressure at 1 bar. The system is equilibrated for $10 \mathrm{~ns}$ in the NPT ensemble with a simulation time step of $2 \mathrm{fs}$. Finally, the production run is carried out for $100 \mathrm{~ns}$ for the primary system. The long-range electrostatic interactions are treated using particle-mesh Ewald sum with a cut-off of $1.0 \mathrm{~nm}$. The van der Waals interactions are terminated beyond the cut-off value of 1.0 $\mathrm{nm}$. The LINCS algorithm is used to constrain all bonds involving hydrogen atoms. All simulations were performed using the GROMACS simulation program. The analyses of the trajectories are performed using GROMACS and MDAnalysis (Michaud-Agrawal et al., 2011)

\section{REFERENCES}

Alves, G.S., Oertel Knöchel, V., Knöchel, C., Carvalho, A.F., Pantel, J., Engelhardt, E., and Laks, 
J. (2015). Integrating retrogenesis theory to Alzheimer's disease pathology: insight from DTITBSS investigation of the white matter microstructural integrity. Biomed Res. Int. 2015, 291658.

Anekonda, T.S., Quinn, J.F., Harris, C., Frahler, K., Wadsworth, T.L., and Woltjer, R.L. (2011). Ltype voltage-gated calcium channel blockade with isradipine as a therapeutic strategy for Alzheimer's disease. Neurobiol. Dis. 41, 62-70.

Arispe, N., Pollard, H.B., and Rojas, E. (1993a). Giant multilevel cation channels formed by Alzheimer disease amyloid beta-protein [A beta P-(1-40)] in bilayer membranes. Proc. Natl. Acad. Sci. 90, 10573-10577.

Arispe, N., Rojas, E., and Pollard, H.B. (1993b). Alzheimer disease amyloid beta protein forms calcium channels in bilayer membranes: blockade by tromethamine and aluminum. Proc. Natl. Acad. Sci. U. S. A. 90, 567-571.

Bartzokis, G. (2011). Alzheimer's disease as homeostatic responses to age-related myelin breakdown. Neurobiol. Aging 32, 1341-1371.

Bernstein, S.L., Dupuis, N.F., Lazo, N.D., Wyttenbach, T., Condron, M.M., Bitan, G., Teplow, D.B., Shea, J.-E., Ruotolo, B.T., Robinson, C. V, et al. (2009). Amyloid- $\beta$ protein oligomerization and the importance of tetramers and dodecamers in the aetiology of Alzheimer's disease. Nat. Chem. 1, 326-331.

Bhowmik, D., Mote, K.R., MacLaughlin, C.M., Biswas, N., Chandra, B., Basu, J.K., Walker, G.C., Madhu, P.K., and Maiti, S. (2015). Cell-Membrane-Mimicking Lipid-Coated Nanoparticles Confer Raman Enhancement to Membrane Proteins and Reveal Membrane-Attached Amyloid-beta Conformation. ACS Nano 9, 9070-9077.

Bieschke, J., Herbst, M., Wiglenda, T., Friedrich, R.P., Boeddrich, A., Schiele, F., Kleckers, D., Lopez del Amo, J.M., Grüning, B.A., Wang, Q., et al. (2011). Small-molecule conversion of toxic oligomers to nontoxic $\beta$-sheet-rich amyloid fibrils. Nat. Chem. Biol. 8, 93-101.

Bitan, G., and Teplow, D.B. (2004). Rapid photochemical cross-linking--a new tool for studies of metastable, amyloidogenic protein assemblies. Acc. Chem. Res. 37, 357-364.

Burns, A., and lliffe, S. (2009). Alzheimer's disease. BMJ 338, b158.

Butterfield, S.M., and Lashuel, H.A. (2010). Amyloidogenic protein-membrane interactions: mechanistic insight from model systems. Angew. Chem. Int. Ed. Engl. 49, 5628-5654.

Cataldo, J.K., Prochaska, J.J., and Glantz, S.A. (2010). Cigarette smoking is a risk factor for Alzheimer's Disease: an analysis controlling for tobacco industry affiliation. J. Alzheimer's Dis. 19, 465-480.

Chen, G., Xu, T., Yan, Y., Zhou, Y., Jiang, Y., Melcher, K., and Xu, H.E. (2017). Amyloid beta: 
structure, biology and structure-based therapeutic development. Acta Pharmacol. Sin. 38, 12051235.

Chi, E.Y., Frey, S.L., and Lee, K.Y.C. (2007). Ganglioside GM1-mediated amyloid-beta fibrillogenesis and membrane disruption. Biochemistry 46, 1913-1924.

Choi, E.S., and Dokholyan, N. V (2021). SOD1 oligomers in amyotrophic lateral sclerosis. Curr. Opin. Struct. Biol. 66, 225-230.

Colletier, J.-P., Chaize, B., Winterhalter, M., and Fournier, D. (2002). Protein encapsulation in liposomes: efficiency depends on interactions between protein and phospholipid bilayer. BMC Biotechnol. 2, 1-8.

Dante, S., Hauss, T., Brandt, A., Dencher, N.A., Hauß, T., Brandt, A., and Dencher, N.A. (2008). Membrane fusogenic activity of the Alzheimer's peptide A beta(1-42) demonstrated by smallangle neutron scattering. J. Mol. Biol. 376, 393-404.

Deane, R., and Zlokovic, B. V (2007). Role of the blood-brain barrier in the pathogenesis of Alzheimer's disease. Curr. Alzheimer Res. 4, 191-197.

DeToma, A.S., Salamekh, S., Ramamoorthy, A., and Lim, M.H. (2012). Misfolded proteins in Alzheimer's disease and type II diabetes. Chem. Soc. Rev. 41, 608-621.

Devarajan, S., and Sharmila, J.S. (2014). Molecular dynamics study of GM1 ganglioside complex with amyloid $\beta$ peptide (Aß42) in lipid membrane. J. Mol. Liq. 195, 59-64.

Du, Y., Du, Y., Zhang, Y., Huang, Z., Fu, M., Li, J., Pang, Y., Lei, P., Wang, Y.T., and Song, W. (2019). MKP-1 reduces $A \beta$ generation and alleviates cognitive impairments in Alzheimer's disease models. Signal Transduct. Target. Ther. 4, 1-12.

Fancy, D.A., and Kodadek, T. (1999). Chemistry for the analysis of protein-protein interactions: rapid and efficient cross-linking triggered by long wavelength light. Proc. Natl. Acad. Sci. 96, 6020-6024.

Fernández-Pérez, E.J., Sepúlveda, F.J., Peoples, R., and Aguayo, L.G. (2017). Role of membrane GM1 on early neuronal membrane actions of $A \beta$ during onset of Alzheimer's disease. Biochim. Biophys. Acta (BBA)-Molecular Basis Dis. 1863, 3105-3116.

Francis, P.T., Palmer, A.M., Snape, M., and Wilcock, G.K. (1999). The cholinergic hypothesis of Alzheimer's disease: a review of progress. J. Neurol. Neurosurg. Psychiatry 66, 137-147.

Gade Malmos, K., Blancas-Mejia, L.M., Weber, B., Buchner, J., Ramirez-Alvarado, M., Naiki, H., and Otzen, D. (2017). ThT 101: a primer on the use of thioflavin T to investigate amyloid formation. Amyloid 24, 1-16.

Glabe, C.G. (2008). Structural classification of toxic amyloid oligomers. J. Biol. Chem. 283, 
29639-29643.

Haass, C., and Selkoe, D.J. (2007). Soluble protein oligomers in neurodegeneration: lessons from the Alzheimer's amyloid beta-peptide. Nat. Rev. Mol. Cell Biol. 8, 101-112.

Hane, F., and Leonenko, Z. (2014). Effect of metals on kinetic pathways of amyloid- $\beta$ aggregation. Biomolecules 4, 101-116.

Hardy, J. (2006). Has the amyloid cascade hypothesis for Alzheimer's disease been proved? Curr. Alzheimer Res. 3, 71-73.

Hardy, J., and Allsop, D. (1991). Amyloid deposition as the central event in the aetiology of Alzheimer's disease. Trends Pharmacol. Sci. 12, 383-388.

Hardy, J.A., and Higgins, G.A. (1992). Alzheimer's disease: the amyloid cascade hypothesis. Science 256, 184-185.

Hellstrand, E., Nowacka, A., Topgaard, D., Linse, S., and Sparr, E. (2013). Membrane lipid coaggregation with a-synuclein fibrils. PLoS One 8, e77235.

Hu, X., Crick, S.L., Bu, G., Frieden, C., Pappu, R. V, and Lee, J.-M. (2009). Amyloid seeds formed by cellular uptake, concentration, and aggregation of the amyloid-beta peptide. Proc. Natl. Acad. Sci. 106, 20324-20329.

Huang, J., Rauscher, S., Nawrocki, G., Ran, T., Feig, M., De Groot, B.L., Grubmüller, H., and MacKerell, A.D. (2017). CHARMM36m: an improved force field for folded and intrinsically disordered proteins. Nat. Methods 14, 71-73.

Ikeda, K., Yamaguchi, T., Fukunaga, S., Hoshino, M., and Matsuzaki, K. (2011). Mechanism of amyloid $\beta$-protein aggregation mediated by GM1 ganglioside clusters. Biochemistry 50, 64336440.

Iversen, L.L., Mortishire-Smith, R.J., Pollack, S.J., and Shearman, M.S. (1995). The toxicity in vitro of beta-amyloid protein. Biochem. J. 311, 1-16.

Jakob-Roetne, R., Jacobsen, H., Jakob-Roetne, R., and Jacobsen, H. (2009). Alzheimer's disease: from pathology to therapeutic approaches. Angew. Chemie Int. Ed. 48, 3030-3059. Jang, H., Zheng, J., and Nussinov, R. (2007). Models of beta-amyloid ion channels in the membrane suggest that channel formation in the bilayer is a dynamic process. Biophys. J. 93, 1938-1949.

Jang, H., Arce, F.T., Ramachandran, S., Capone, R., Azimova, R., Kagan, B.L., Nussinov, R., and Lal, R. (2010). Truncated $\beta$-amyloid peptide channels provide an alternative mechanism for Alzheimer's Disease and Down syndrome. Proc. Natl. Acad. Sci. 107, 6538 LP - 6543. 
Jo, S., Kim, T., lyer, V.G., and Im, W. (2008). CHARMM-GUI: a web-based graphical user interface for CHARMM. J. Comput. Chem. 29, 1859-1865.

Kagan, B.L., Hirakura, Y., Azimov, R., Azimova, R., and Lin, M.-C. (2002). The channel hypothesis of Alzheimer's disease: current status. Peptides 23, 1311-1315.

Kakio, A., Nishimoto, S., Yanagisawa, K., Kozutsumi, Y., and Matsuzaki, K. (2001). Cholesteroldependent formation of GM1 ganglioside-bound amyloid $\beta$-protein, an endogenous seed for Alzheimer amyloid. J. Biol. Chem. 276, 24985-24990.

Kakio, A., Nishimoto, S., Yanagisawa, K., Kozutsumi, Y., and Matsuzaki, K. (2002). Interactions of amyloid $\beta$-protein with various gangliosides in raft-like membranes: importance of GM1 ganglioside-bound form as an endogenous seed for Alzheimer amyloid. Biochemistry 41, 73857390.

Kandimalla, R., Vallamkondu, J., Corgiat, E.B., and Gill, K.D. (2016). Understanding Aspects of Aluminum Exposure in Alzheimer's Disease Development. Brain Pathol. 26, 139-154.

Karran, E., Mercken, M., and Strooper, B. De (2011). The amyloid cascade hypothesis for Alzheimer's disease: an appraisal for the development of therapeutics. Nat. Rev. Drug Discov. 10, 698.

Klein, W.L., Krafft, G.A., and Finch, C.E. (2001). Targeting small Abeta oligomers: the solution to an Alzheimer's disease conundrum? Trends Neurosci. 24, 219-224.

Kremer, J.R., Mastronarde, D.N., and Mclntosh, J.R. (1996). Computer visualization of threedimensional image data using IMOD. J. Struct. Biol. 116, 71-76.

Lambert, M.P., Viola, K.L., Chromy, B.A., Chang, L., Morgan, T.E., Yu, J., Venton, D.L., Krafft, G.A., Finch, C.E., and Klein, W.L. (2001). Vaccination with soluble Abeta oligomers generates toxicity-neutralizing antibodies. J. Neurochem. 79, 595-605.

Ledeen, R.W., and Wu, G. (2015). The multi-tasked life of GM1 ganglioside, a true factotum of nature. Trends Biochem. Sci. 40, 407-418.

Luo, J., Yu, C.-H., Yu, H., Borstnar, R., Kamerlin, S.C.L., Gra $\square$ slund, A., Abrahams, J.P., and $\mathrm{Wa} \square \mathrm{rmla} \square$ nder, S.K.T.S. (2013). Cellular polyamines promote amyloid-beta (A $\beta$ ) peptide fibrillation and modulate the aggregation pathways. ACS Chem. Neurosci. 4, 454-462.

Mantyh, P.W., Ghilardi, J.R., Rogers, S., DeMaster, E., Allen, C.J., Stimson, E.R., and Maggio, J.E. (1993). Aluminum, iron, and zinc ions promote aggregation of physiological concentrations of $\beta$-amyloid peptide. J. Neurochem. 61, 1171-1174.

Martinez Hernandez, A., Urbanke, H., Gillman, A.L., Lee, J., Ryazanov, S., Agbemenyah, H.Y., Benito, E., Jain, G., Kaurani, L., Grigorian, G., et al. (2018). The diphenylpyrazole compound 
anle138b blocks Abeta channels and rescues disease phenotypes in a mouse model for amyloid pathology. EMBO Mol. Med. 10, 32-47.

Matsumura, S., Shinoda, K., Yamada, M., Yokojima, S., Inoue, M., Ohnishi, T., Shimada, T., Kikuchi, K., Masui, D., and Hashimoto, S. (2011). Two distinct amyloid $\beta$-protein (A $\beta$ ) assembly pathways leading to oligomers and fibrils identified by combined fluorescence correlation spectroscopy, morphology, and toxicity analyses. J. Biol. Chem. 286, 11555-11562.

Matsuzaki, K. (2014). How do membranes initiate Alzheimer's Disease? Formation of toxic amyloid fibrils by the amyloid $\beta$-protein on ganglioside clusters. Acc. Chem. Res. 47, 2397-2404. Michaud-Agrawal, N., Denning, E.J., Woolf, T.B., and Beckstein, O. (2011). MDAnalysis: a toolkit for the analysis of molecular dynamics simulations. J. Comput. Chem. 32, 2319-2327.

Micsonai, A., Wien, F., Bulyáki, É., Kun, J., Moussong, É., Lee, Y.-H., Goto, Y., Réfrégiers, M., and Kardos, J. (2018). BeStSel: a web server for accurate protein secondary structure prediction and fold recognition from the circular dichroism spectra. Nucleic Acids Res. 46, W315-W322. Miklossy, J. (2011). Alzheimer's disease - a neurospirochetosis. Analysis of the evidence following Koch's and Hill's criteria. J. Neuroinflammation 8, 90.

Mudher, A., and Lovestone, S. (2002). Alzheimer's disease-do tauists and baptists finally shake hands? Trends Neurosci. 25, 22-26.

Mufamadi, M.S., Pillay, V., Choonara, Y.E., Du Toit, L.C., Modi, G., Naidoo, D., and Ndesendo, V.M.K. (2011). A review on composite liposomal technologies for specialized drug delivery. J. Drug Deliv. 2011.

Nishio, M., Fukumoto, S., Furukawa, K., Ichimura, A., Miyazaki, H., Kusunoki, S., Urano, T., and Furukawa, K. (2004). Overexpressed GM1 suppresses nerve growth factor (NGF) signals by modulating the intracellular localization of NGF receptors and membrane fluidity in PC12 cells. J. Biol. Chem. 279, 33368-33378.

Okada, T., Wakabayashi, M., Ikeda, K., and Matsuzaki, K. (2007). Formation of toxic fibrils of Alzheimer's amyloid $\beta$-protein-(1-40) by monosialoganglioside GM1, a neuronal membrane component. J. Mol. Biol. 371, 481-489.

Pandey, A.P., Haque, F., Rochet, J.-C., and Hovis, J.S. (2011). a-Synuclein-induced tubule formation in lipid bilayers. J. Phys. Chem. B 115, 5886-5893.

Park, J.G., and Palmer, A.E. (2015). Measuring the in situ Kd of a genetically encoded Ca2+ sensor. Cold Spring Harb. Protoc. 2015, pdb-prot076554.

Pisa, D., Alonso, R., Rábano, A., Rodal, I., and Carrasco, L. (2015). Different brain regions are infected with fungi in Alzheimer's disease. Sci. Rep. 5, 15015. 
Proctor, E., Fee, L., Tao, Y., Redler, R., Fay, J., Zhang, Y., Lv, Z., Mercer, I., Deshmukh, M., Lyubchenko, Y., et al. Nonnative SOD1 trimer is toxic to motor neurons in a model of amyotrophic lateral sclerosis. 113, 614-619.

Proctor, E.A., Fee, L., Tao, Y., Redler, R.L., Fay, J.M., Zhang, Y., Lv, Z., Mercer, I.P., Deshmukh, M., Lyubchenko, Y.L., et al. (2015). Nonnative SOD1 trimer is toxic to motor neurons in a model of amyotrophic lateral sclerosis. Proc. Natl. Acad. Sci. 113, 614-619.

Quist, A., Doudevski, I., Lin, H., Azimova, R., Ng, D., Frangione, B., Kagan, B., Ghiso, J., and Lal, R. (2005). Amyloid ion channels: a common structural link for protein-misfolding disease. Proc. Natl. Acad. Sci. U. S. A. 102, 10427-10432.

Redler, R.L., Fee, L., Fay, J.M., Caplow, M., and Dokholyan, N. V (2014). Non-native soluble oligomers of $\mathrm{Cu} / \mathrm{Zn}$ superoxide dismutase (SOD1) contain a conformational epitope linked to cytotoxicity in amyotrophic lateral sclerosis (ALS). Biochemistry 53, 2423-2432.

Reynolds, N.P., Soragni, A., Rabe, M., Verdes, D., Liverani, E., Handschin, S., Riek, R., and Seeger, S. (2011). Mechanism of membrane interaction and disruption by a-synuclein. J. Am. Chem. Soc. 133, 19366-19375.

Sanghera, N., Correia, B.E.F.S., Correia, J.R.S., Ludwig, C., Agarwal, S., Nakamura, H.K., Kuwata, K., Samain, E., Gill, A.C., and Bonev, B.B. (2011). Deciphering the molecular details for the binding of the prion protein to main ganglioside GM1 of neuronal membranes. Chem. Biol. 18, 1422-1431.

Di Scala, C., Yahi, N., Boutemeur, S., Flores, A., Rodriguez, L., Chahinian, H., and Fantini, J. (2016). Common molecular mechanism of amyloid pore formation by Alzheimer's $\beta$-amyloid peptide and a-synuclein. Sci. Rep. 6, 28781.

Schwede, T., Kopp, J., Guex, N., and Peitsch, M.C. (2003). SWISS-MODEL: an automated protein homology-modeling server. Nucleic Acids Res. 31, 3381-3385.

Shirwany, N.A., Payette, D., Xie, J., and Guo, Q. (2007). The amyloid beta ion channel hypothesis of Alzheimer's disease. Neuropsychiatr. Dis. Treat. 3, 597.

Van Der Spoel, D., Lindahl, E., Hess, B., Groenhof, G., Mark, A.E., and Berendsen, H.J.C. (2005). GROMACS: fast, flexible, and free. J. Comput. Chem. 26, 1701-1718.

Su, B., Wang, X., Nunomura, A., Moreira, P.I., Lee, H., Perry, G., Smith, M.A., and Zhu, X. (2008). Oxidative stress signaling in Alzheimer's disease. Curr. Alzheimer Res. 5, 525-532.

Tachi, Y., Okamoto, Y., and Okumura, H. (2019). Conformational change of amyloid- $\beta 40$ in association with binding to GM1-glycan cluster. Sci. Rep. 9, 1-11.

Tanzi, R.E., and Bertram, L. (2005). Twenty years of the Alzheimer's disease amyloid hypothesis: 
a genetic perspective. Cell 120, 545-555.

Thal, D.R., Walter, J., Saido, T.C., and Fändrich, M. (2015). Neuropathology and biochemistry of $A \beta$ and its aggregates in Alzheimer's disease. Acta Neuropathol. 129, 167-182.

Varkey, J., Isas, J.M., Mizuno, N., Jensen, M.B., Bhatia, V.K., Jao, C.C., Petrlova, J., Voss, J.C., Stamou, D.G., Steven, A.C., et al. (2010). Membrane curvature induction and tubulation are common features of synucleins and apolipoproteins. J. Biol. Chem. 285, 32486-32493.

Vos, T., Allen, C., Arora, M., Barber, R.M., Bhutta, Z.A., Brown, A., Carter, A., Casey, D.C., Charlson, F.J., and Chen, A.Z. (2016). Global, regional, and national incidence, prevalence, and years lived with disability for 310 diseases and injuries, 1990-2015: a systematic analysis for the Global Burden of Disease Study 2015. Lancet 388, 1545-1602.

Yagi-Utsumi, M., Matsuo, K., Yanagisawa, K., Gekko, K., and Kato, K. (2010). Spectroscopic Characterization of Intermolecular Interaction of Amyloid $\beta$ Promoted on GM1 Micelles. Int. J. Alzheimers. Dis. 2011, 925073.

Yamamoto, N., Matsubara, T., Sato, T., and Yanagisawa, K. (2008). Age-dependent high-density clustering of GM1 ganglioside at presynaptic neuritic terminals promotes amyloid $\beta$-protein fibrillogenesis. Biochim. Biophys. Acta (BBA)-Biomembranes 1778, 2717-2726.

Yanagisawa, K. (2005). GM1 ganglioside and the seeding of amyloid in Alzheimer's disease: endogenous seed for Alzheimer amyloid. Neurosci. 11, 250-260.

Yanagisawa, K., Odaka, A., Suzuki, N., and Ihara, Y. (1995). GM1 ganglioside--bound amyloid $\beta$ -protein $(A \beta)$ : A possible form of preamyloid in Alzheimer's disease. Nat. Med. 1, 1062.

Zhu, C., Beck, M. V., Griffith, J.D., Deshmukh, M., and Dokholyan, N. V. (2018). Large SOD1 aggregates, unlike trimeric SOD1, do not impact cell viability in a model of amyotrophic lateral sclerosis. Proc. Natl. Acad. Sci. 115, 201800187.

\section{ACKNOWLEDGEMENTS}

We acknowledge support from the National Institutes for Health 1R35 GM134864, the Huck Institutes of the Life Sciences, and the Passan Foundation. The project described was also supported by the National Center for Advancing Translational Sciences, National Institutes of Health, through Grant UL1 TR002014. The content is solely the responsibility of the authors and does not necessarily represent the official views of the 
bioRxiv preprint doi: https://doi.org/10.1101/2021.07.22.453392; this version posted July 22, 2021. The copyright holder for this preprint (which was not certified by peer review) is the author/funder. All rights reserved. No reuse allowed without permission.

NIH. We also acknowledge the help from Brianna L. Hnath, Martin Dokholyan and Sophia Dokholyan with the purification of membrane $A \beta$ oligomers. 


\section{FIGURES}

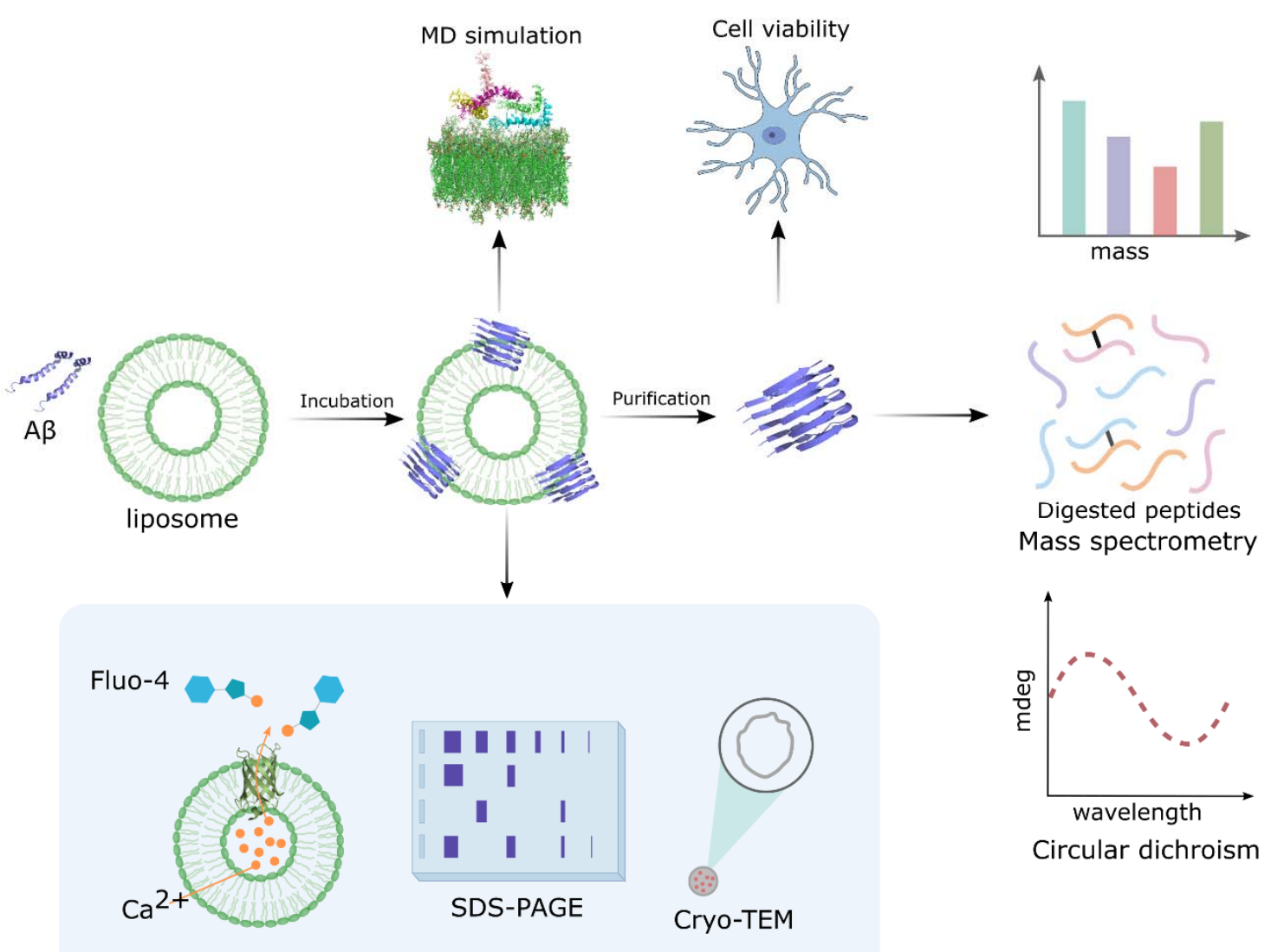

Figure 1. Schematic of the hypothesis and the design. We incubate $A \beta$ with GM1 liposomes to determine the effect of GM1 membrane on the formation of $A \beta$ fibrils and oligomers. We perform MD simulation to explore the interaction between $A \beta$ and $G M 1$ membrane. We purify the $A \beta$ oligomers formed on liposomes membrane, determine the toxicity, and characterize the structure with $C D$ and mass spectrometry. We design a calcium-encapsulation assay to provide new evidences for the $A \beta$ ion channel hypothesis. We also determine the effect of $A \beta$ on the morphology of liposomes membrane using Cryo-TEM. 
A

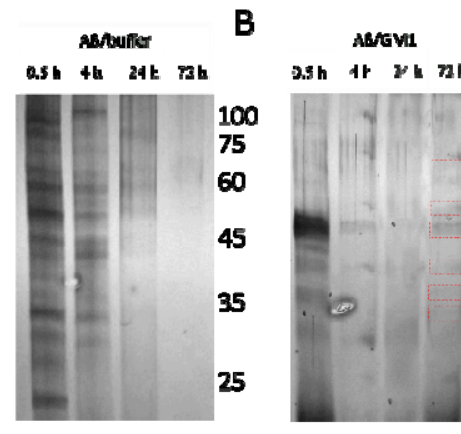

$\mathbf{F}$

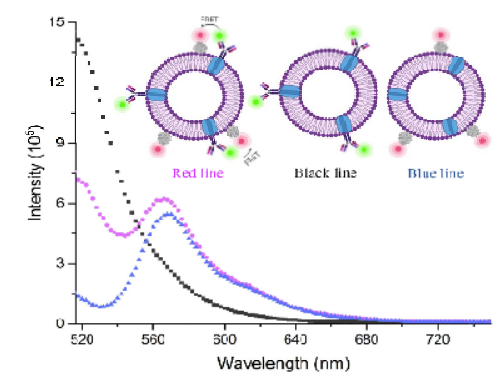

C

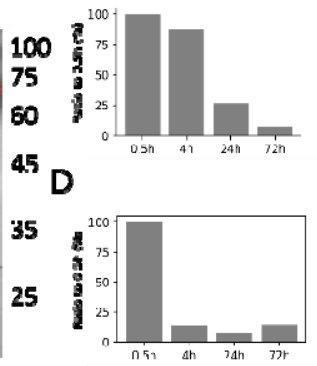

G

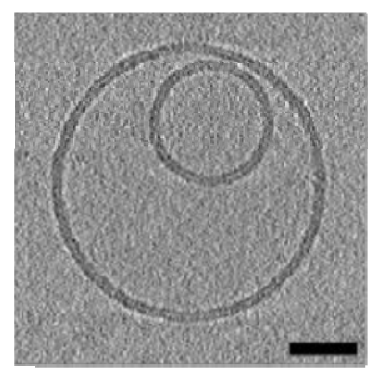

$\mathbf{E}$

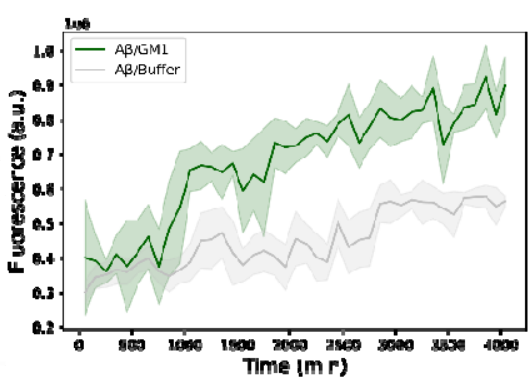

H

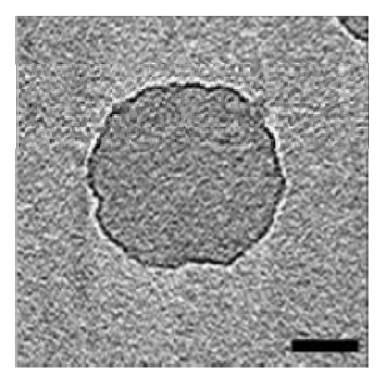

Figure 2. Interaction between $A \boldsymbol{\beta}$ and GM1 liposome. (A), (B) SDS-PAGE and silver staining results of $A \beta$ oligomers formed in the presence and absence of GM1 liposomes at different time points. (C), (D) Quantitative analysis of $A \beta$ oligomers formed in the presence and absence of GM1 liposomes at different time points. $(E)$ The formation of $A \beta$ fibrils is identified by ThT. (F) FRET results of GM1 and $A \beta$. The donor is Alexa Fluor ${ }^{\circledR} 4886 E 10$, the antibody of $A \beta$. The acceptor is Alexa Fluor ${ }^{\text {TM }} 555$ CTSB, a molecule that specifically binds to GM1. Red curve: $A \beta$, GM1 liposomes, donor and acceptor. Black curve: $A \beta, G M 1$ liposomes and donor. Blue curve: $A \beta$, GM1 liposomes and acceptor. (G\&H) An approximately 10-nm thick digital slices through tomograms of liposomes incubated with $(G)$ or without $A \beta(H)$. The lipid bilayer is visible in the untreated sample and only a monolayer is visible after treatment. Scale bars represent 50 microns. 
A

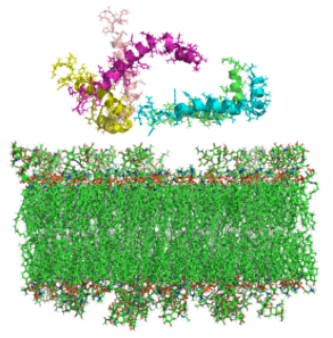

B

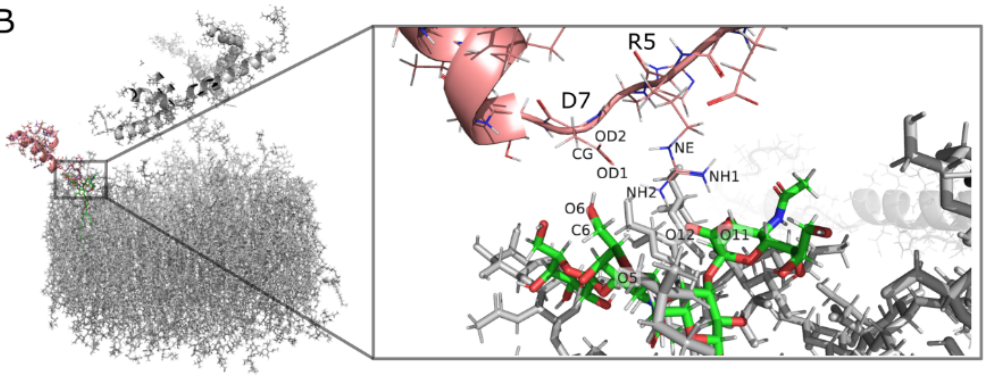

C

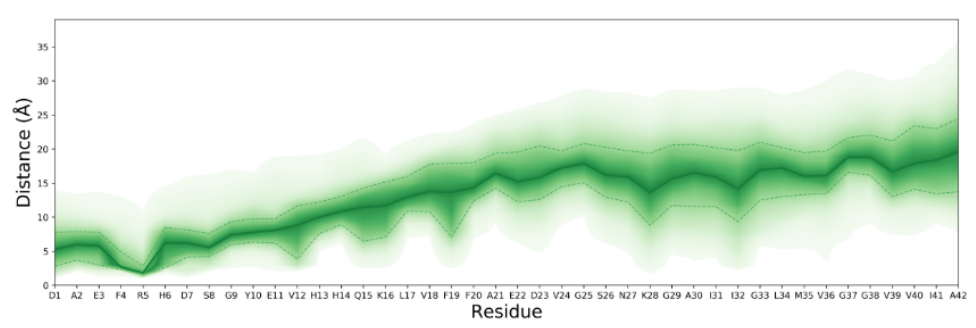

$\mathrm{E}$

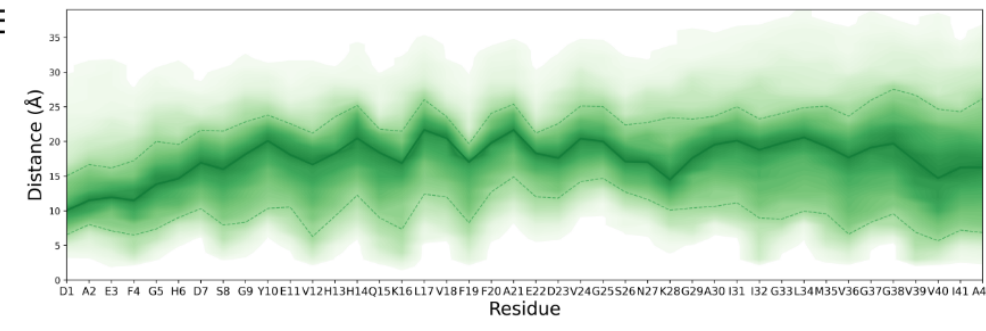

G

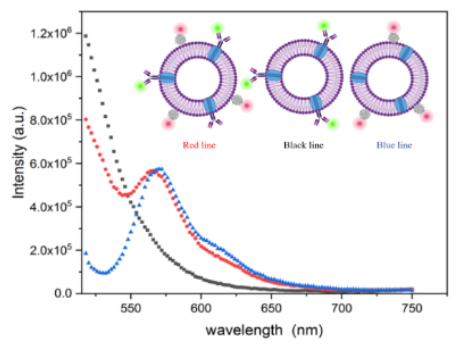

$\mathrm{H}$

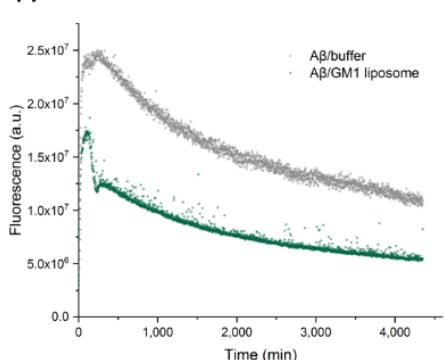

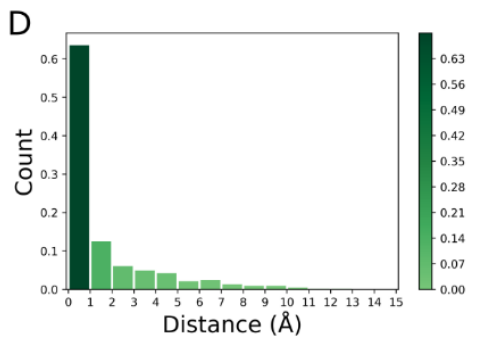

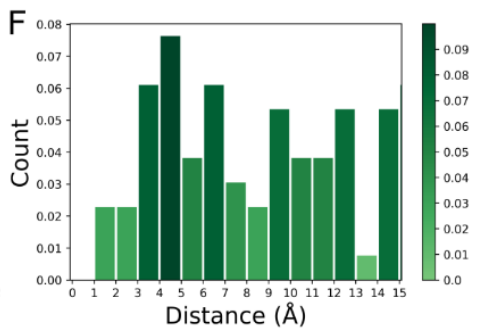

I

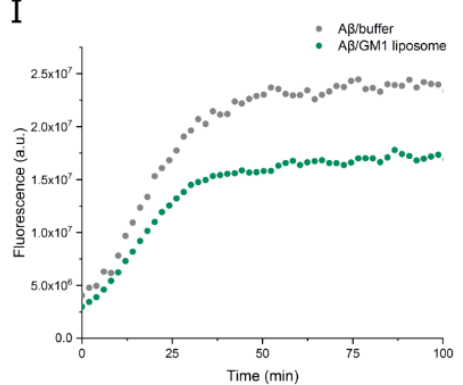

Figure 3. Interaction between wild type, mutant $A \beta$, and GM1 liposome. (A) The initial structure for the molecular dynamics simulation of GM1 membrane and 5 A $\beta$ monomers. (B) The $3 \mathrm{D}$ view of the atoms in the interacting interface between R5 and GM1. (C) The distances between atoms of each residue in wild type $A \beta$ and atoms of all GM1 in the membrane. (D) The histogram of the minimum distances between R5 in $A \beta$ and $G M 1$ in the membrane of all steps in the MD simulation. (E) The distances between the $A \beta$ mutant $R 5 G$ and GM1. (F) The histogram of the minimum distances between $G 5$ and GM1. G5 is the fifth residue in the A mutant R5G. (G) FRET between R5G and GM1. The donor is Alexa Fluor ${ }^{\circledR} 4886 \mathrm{E} 10$, the antibody of $A \beta$. The acceptor is Alexa FluorTM 555 CTSB, a molecule that specifically binds to GM1. Red curve: mutant $A \beta, G M 1$ liposomes, donor and acceptor. Black curve: mutant $A \beta, G M 1$ liposomes and 
donor. Blue curve: mutant $A \beta, G M 1$ liposomes and acceptor. $(H)$ The formation of mutant $A \beta$ (R5G) fibrils are identified by ThT. (I) The formation of mutant $A \beta$ (R5G) fibrils in the first 100 min.

A

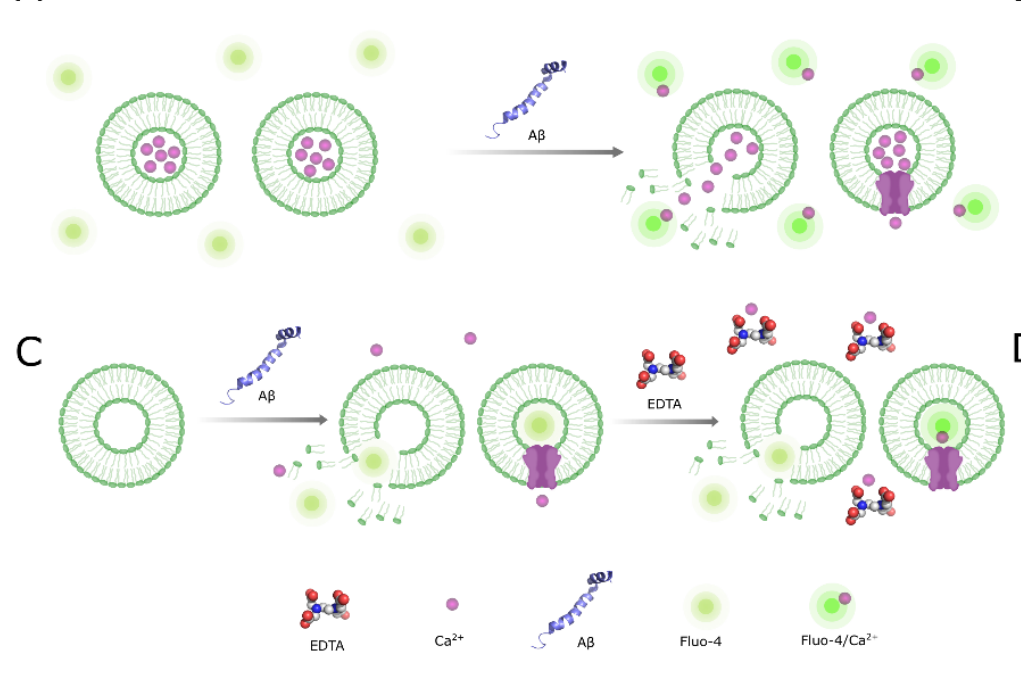

B

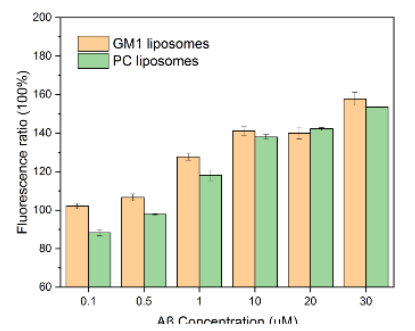

D

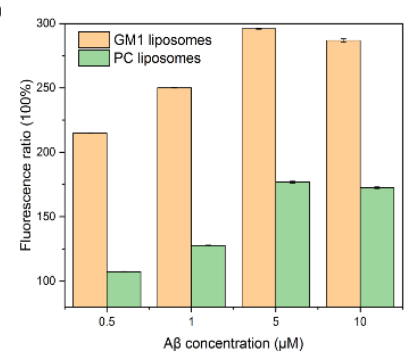

Figure 4. (A) Schematic of the experimental design to prove the formation of $A \beta$ ion channels with $\mathrm{Ca}^{2+}$-encapsulated GM1 liposomes. (B) The ratio of the fluorescence intensity of $\mathrm{Ca}^{2+}$ encapsulated liposomes incubated with $A \beta$ to that without $A \beta$. (C) Schematic of the experimental design to prove the formation of $A \beta$ ion channels with dye-encapsulated GM1 liposomes. (D) The ratio of the fluorescence intensity of dye-encapsulated liposomes incubated with $A \beta$ to that without $A \beta$. 
bioRxiv preprint doi: https://doi.org/10.1101/2021.07.22.453392; this version posted July 22, 2021. The copyright holder for this preprint (which was not certified by peer review) is the author/funder. All rights reserved. No reuse allowed without permission.

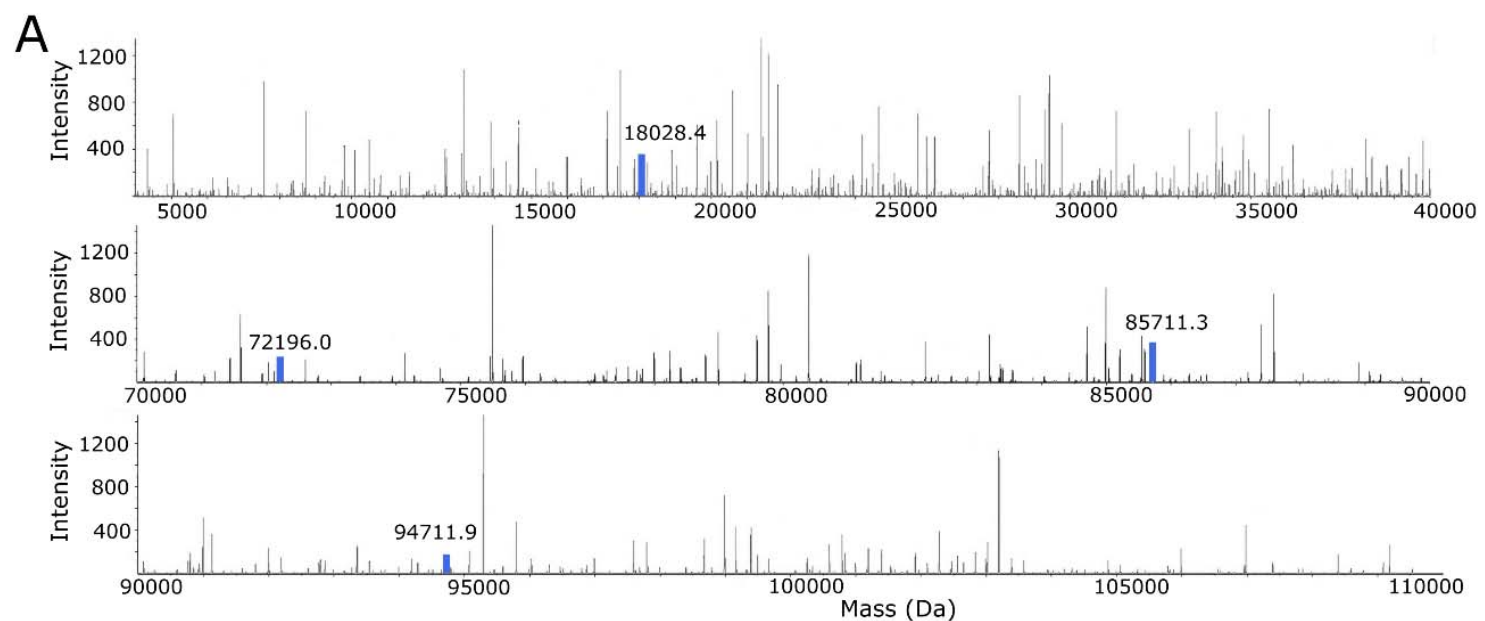

B

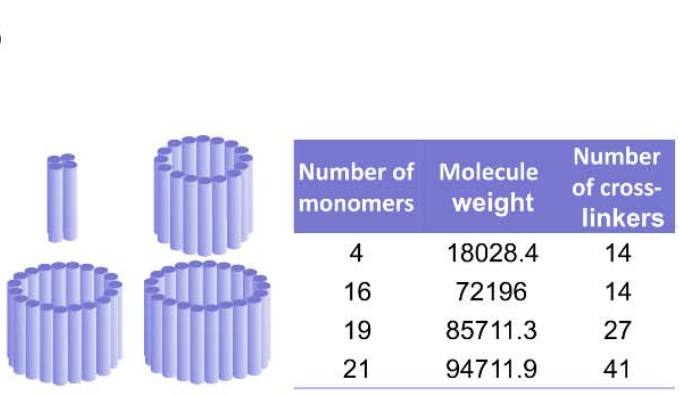

D

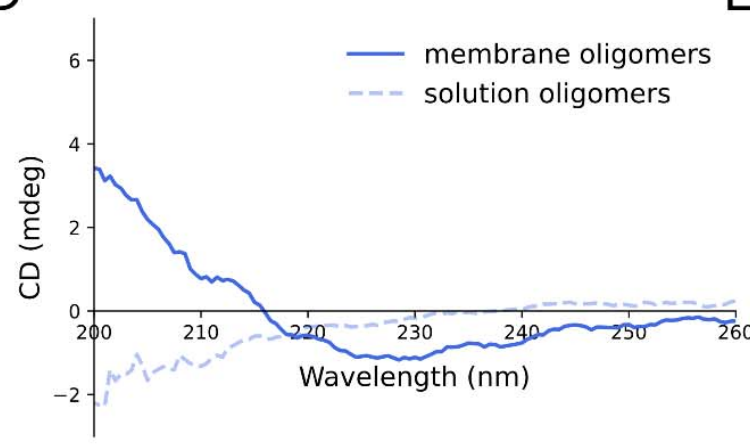

F

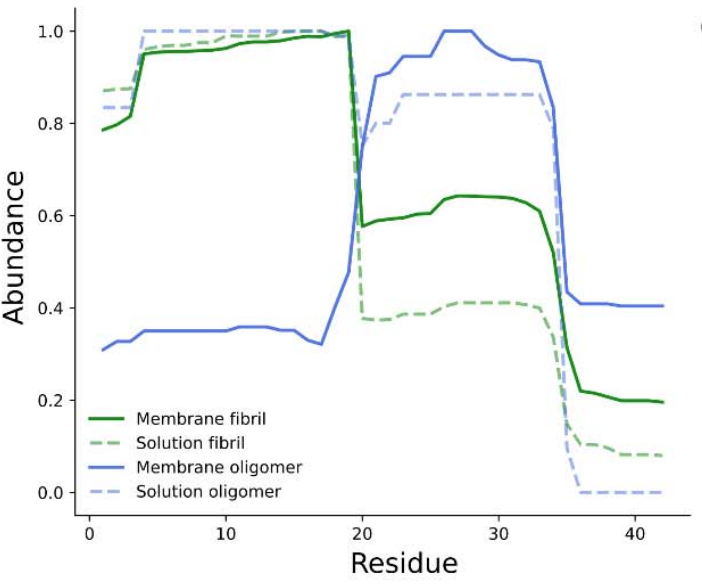

C

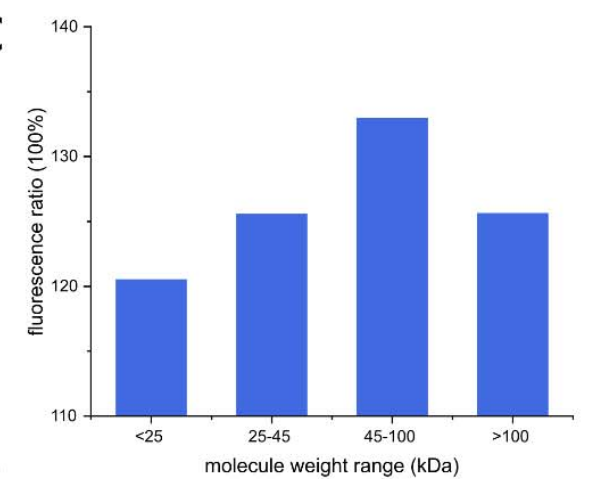

E

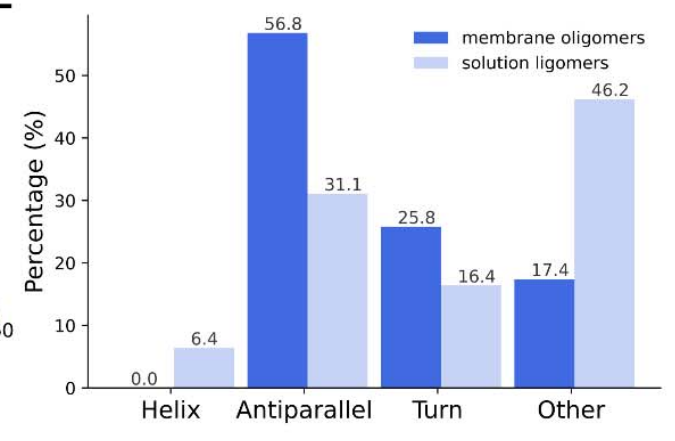

G

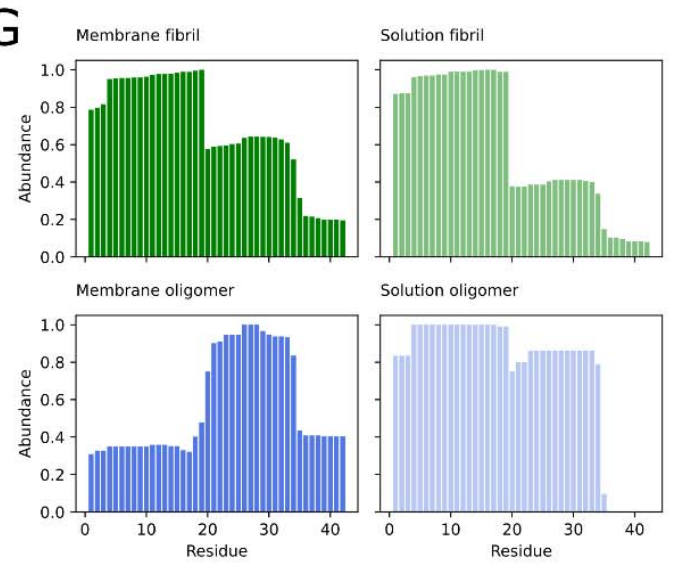


Figure 5. Structure characterization of membrane $A \beta$ oligomers. $(A)$ After purification, the molecule weights of $A \beta$ oligomers are analyzed by mass spectrometer. (B) Based on the results of mass spectrometry, there are four possible cross-linked $A \beta$ oligomer species that may form ion channels. (C) We divide the membrane $A \beta$ oligomers into four samples according to the molecular weights. Then, we incubate the four samples with the $\mathrm{Ca}^{2+}$-encapsulated liposome and determine the fluorescence intensity. (D), (E) The secondary structure of the A oligomers formed in the presence and absence of GM1 liposomes. $(F),(G)$ The residue abundance of $A \beta$ oligomers and fibrils formed in the presence and absence of GM1 liposomes.

A
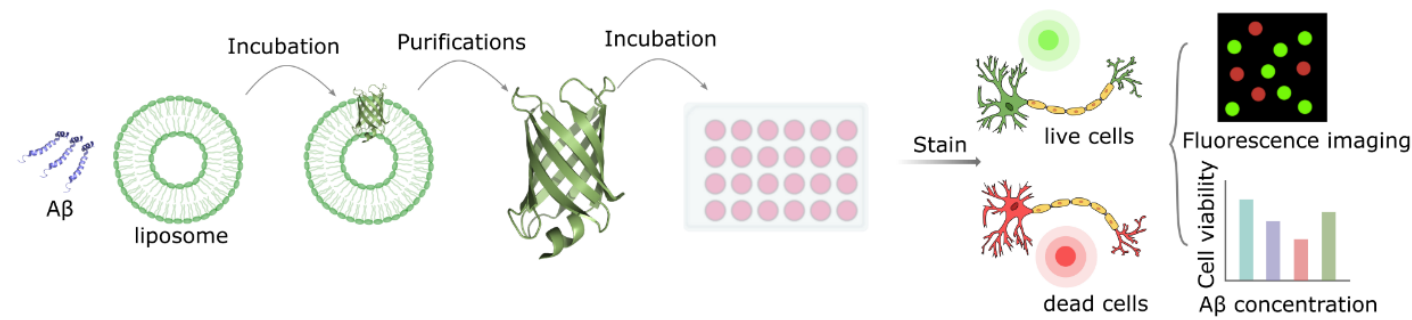

B
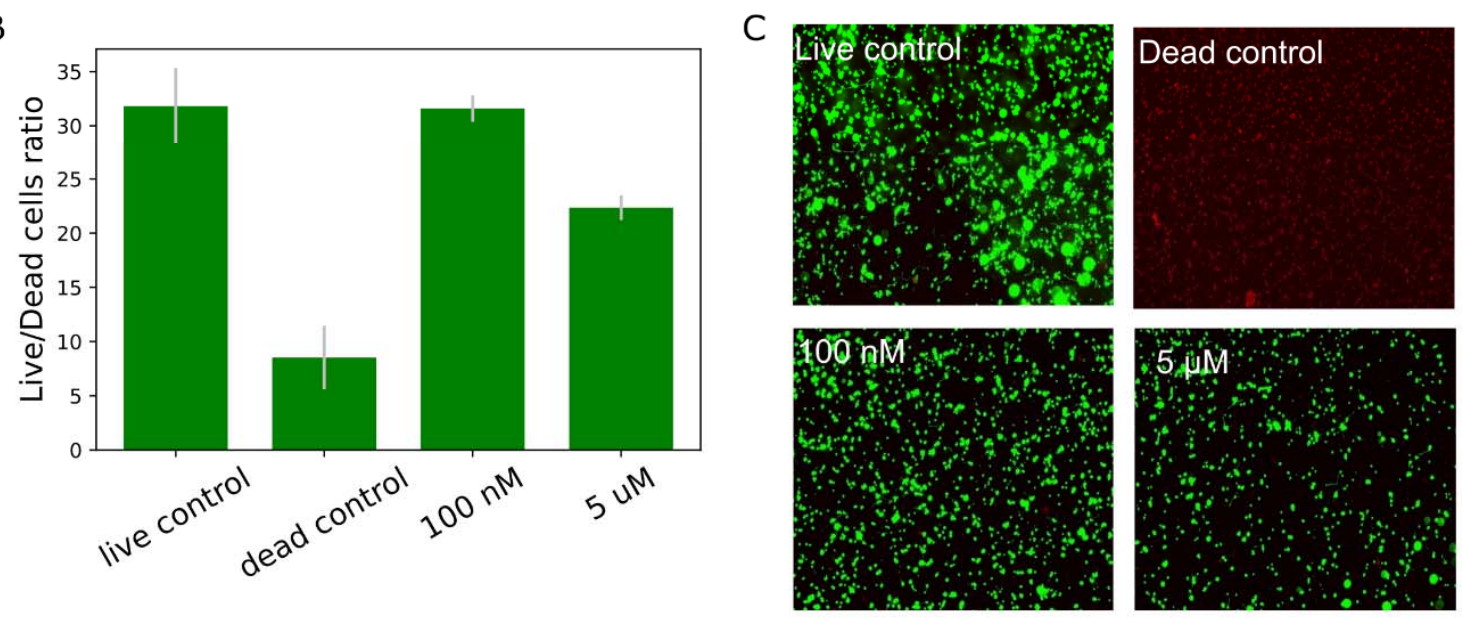

Figure 6. $A \beta$ oligomers formed on liposome membranes are cytotoxic. (A) Schematic of cell viability experiment. (B) $P C-12$ cells incubated with and without $A \beta$ oligomers. Cell viability is assessed by Calcein AM/ethidium homodimer-1 and calculated by the ratio of dead cells to live cells. (C) PC-12 cells incubated with $A \beta$ oligomers of different concentration. Live cells are stained by Calcein AM in green and dead cells are stained by ethidium homodimer- 1 in red. 